NBER WORKING PAPER SERIES

\title{
STICKING TO YOUR PLAN: THE ROLE OF PRESENT BIAS FOR CREDIT CARD PAYDOWN
}

\author{
Theresa Kuchler \\ Michaela Pagel \\ Working Paper 24881 \\ http://www.nber.org/papers/w24881 \\ NATIONAL BUREAU OF ECONOMIC RESEARCH \\ 1050 Massachusetts Avenue \\ Cambridge, MA 02138 \\ August 2018
}

Previously circulated as "Sticking to Your Plan: Hyperbolic Discounting and Credit Card Debt Paydown". Numerous seminar participants at Stanford, UNC Kenan-Flagler, Yale SOM, Notre Dame, Kellogg, Minnesota Carlson, Brown, Olin, MSU, NYU Stern, the Federal Reserve Board, the New York Federal Reserve, the Philadelphia Federal Reserve, the Federal Reserve Bank of Boston, Harvard Business School, LMU Munich, Cornell University, Princeton University, the $\mathrm{CFPB}$, as well as conference participants at the Aspen Conference on Economic Decision Making, the SITE Summer Workshop, the Red Rock Finance Conference, and the Christmas Meeting of the German Economists Abroad provided insightful comments. We thank Liran Einav, Caroline Hoxby and Jonathan Levin for their tremendous advice and guidance. We also benefited from conversations with Sumit Agarwal, Juliane Begenau, Doug Bernheim, Tim Bresnahan, George Bulman, Dominic Coey, Xavier Gabaix, Simon Hilpert, Harrison Hong, Alejandro Molnar, Juliana Salomao, Paulo Somaini, Denis Sosyura, Charles Sprenger, Luke Stein, Johannes Stroebel, and Jeremy Tobacman. We are grateful to the team at ReadyForZero for providing the data and making this research possible, especially to Rod Ebrahimi and Ignacio Thayer. Financial support to Theresa Kuchler from the B.F. Haley and E.S. Shaw Fellowship through SIEPR is gratefully acknowledged. The views expressed herein are those of the authors and do not necessarily reflect the views of the National Bureau of Economic Research.

NBER working papers are circulated for discussion and comment purposes. They have not been peer-reviewed or been subject to the review by the NBER Board of Directors that accompanies official NBER publications.

(C) 2018 by Theresa Kuchler and Michaela Pagel. All rights reserved. Short sections of text, not to exceed two paragraphs, may be quoted without explicit permission provided that full credit, including $\odot$ notice, is given to the source. 
Sticking to Your Plan: The Role of Present Bias for Credit Card Paydown

Theresa Kuchler and Michaela Pagel

NBER Working Paper No. 24881

August 2018

JEL No. D03,D14,G02

\begin{abstract}
$\underline{\text { ABSTRACT }}$
Using high-frequency transaction-level income, spending, balances, and credit limits data from an online financial service, we show that many consumers fail to stick to their self-set debt paydown plans and argue that this behavior is best explained by a model of present bias. Theoretically, we show that (i) a present-biased agent's sensitivity of consumption spending to paycheck receipt reflects his or her short-run impatience and that (ii) this sensitivity varies with available resources only for agents who are aware (sophisticated) rather than unaware (naive) of their future impatience. In turn, we classify users in our data accordingly. Consistent with present bias, we find that (i) sophisticated users' average paydown falls with higher measured impatience and that (ii) their planned paydown is more predictive of actual paydown than that of naives. We are the first to provide a theoretically-founded empirical methodology to measure sophistication and naivete from spending and income data and to validate this measure using our information on planned versus actual debt paydown. Moreover, our results highlight the importance of distinguishing between sophisticated and naive present-biased individuals in understanding their financial decision making.
\end{abstract}

Theresa Kuchler

Stern School of Business

New York University

44 West 4th Street

New York, NY 10012

tkuchler@stern.nyu.edu

Michaela Pagel

Columbia Business School

3022 Broadway

Uris Hall

New York, NY 10027

and NBER

mpagel@columbia.edu 
In the United States, the majority of households have at least one credit card and more than half carry balances from month to month. With interest-bearing debt in the thousands of dollars per balance-carrying household and median interest rates at $12 \%$ in 2013 , the monthly cost of interest to the average household is substantial (Bricker et al., 2014). At such cost, the extent of credit card debt is puzzling and previous work has documented a variety of behaviors in credit markets that are hard to reconcile with standard motives for borrowing (see, for instance, Laibson, Repetto and Tobacman, 2003; Agarwal et al., 2015; Keys and Wang, 2016; Agarwal and Mazumder, 2013; Agarwal et al., 2010, 2008).

Behavioral economists have proposed a potential explanation for the observed extent of household borrowing: present bias (e.g., Strotz, 1955; Akerlof, 1991; O'Donoghue and Rabin, 1999; Angeletos et al., 2001; Ausubel, 1991; Meier and Sprenger, 2010). According to this explanation, individuals are overly impatient in the short run relative to their long-run preferences. They borrow excessively and often fail to repay later, despite a genuine intention to reduce their debt. Moreover, the prior literature has argued that whether individuals are aware (sophisticated) or unaware (naive), following the terminology of O'Donoghue and Rabin (1999), about the difference in their short-run and long-run preferences can matter substantially for the behavior predicted by models of present bias. Additionally, the distinction between sophistication and naivete is of crucial importance for policy considerations and regulation. In this paper, we propose an empirical measure that captures both aspects of an individual's present bias - the extent of short-run impatience and her sophistication. We apply and validate our proposed measures in a sample of consumers struggling with credit card debt and show that present bias plays an important role in understanding debt paydown behavior.

We use a unique dataset on planned and actual debt paydown to document that many consumers fail to follow through with self-set debt paydown plans. We then present a theoretical model that suggests empirical measures for both features of an individual's present bias: the level of short-run impatience and the individual's awareness of her impatience. Using these measures of both features of present bias, we estimate their role in individual debt paydown behavior. We find that debt paydown decreases with higher measured impatience for sophisticated individuals and that planned paydown is substantially more predictive of actual paydown for sophisticated than for naive individuals. Our results show that considering an individual's potential present bias and, importantly, the individual's awareness of their own present bias (sophistication), significantly improves our understanding of his or her debt repayment patterns.

We study a sample of consumers who signed up for an online financial management service. The data contain the daily balances and transactions on all of their bank accounts and credit cards. Upon joining the service, users make a plan of how much they would like to reduce their debt balances each month. This feature allows us to evaluate success in debt paydown relative to a user's original plan. We find that planned debt paydown is predictive of actual paydown. In fact, no other characteristic, such as monthly income or original debt levels, significantly affects actual paydown once the user's original plan is controlled for. However, most users fall substantially short of their original paydown plans. For each dollar of planned paydown, the average user only reduces debt by 25 to 30 cents.

To understand whether present bias can explain this shortfall in actual relative to originally planned paydown, we suggest a novel way to use the information on high-frequency consumption spending 
in the data to measure an individual's present bias. We present a model to theoretically found our methodology to measure individual short-run impatience as well as the degree to which individuals are aware of their impatience, classifying them as aware (sophisticated) or unaware (naive).

Our theoretical model of present bias suggests an empirical test for the degree of short-run impatience based on the co-movement of consumption and income: more impatient individuals consume more immediately after receiving their paycheck, and then their consumption declines until the next paycheck. ${ }^{1}$ To measure each individual's level of impatience, we thus estimate the degree of such behavior using expenditures for goods which are instantly consumed, such as restaurant meals. Moreover, we filter out the impact of other possible explanations, such as short-term credit constraints. Our model further suggests an empirical test for sophistication: unlike naive consumers, sophisticated consumers act more patiently when they have more available resources, and their consumption between paychecks becomes more even. To estimate how consumption sensitivity to paycheck varies with the level of resources for each user, we exploit within-individual variation in resources over time. We address the potential endogeneity of available resources to consumption patterns by instrumenting with hypothetical balances based on regular, non-discretionary payments such as monthly rent. Based on these estimates, we classify individuals as sophisticated or naive. We then relate these measures of both features of individual present bias, short-run impatience and sophistication, to their debt paydown behavior.

Our model and the previous literature on present bias also predict that it is attractive for presentbiased individuals to delay paying down debt from the current to the next pay cycle. This behavior allows them to avoid reducing consumption in the current pay cycle, when it is particularly valued. At the same time, the long-run cost of debt paid off one paycycle (two weeks) later is small. Since delaying repayment for one paycycle is attractive, individuals may be tempted to repeatedly delay making their payments and naive agents are particularly prone to do so. They are unaware of their future impatience, so they plan to repay their debt in the next pay cycle when they (incorrectly) believe they will be more patient. They do not realize that, when faced with the same decision in the future, they will repeatedly want to delay debt paydown. Thus, naive individuals will often not actually succeed in paying off their debt, despite their plans and intentions to do so. Unlike naives, sophisticated agents are aware of their future impatience, allowing them to recognize and avoid the temptation to repeatedly delay, making them more successful at following through with their debt paydown plans.

Empirically, we find that planned paydown is indeed significantly more predictive of actual paydown for users classified as sophisticated relative to naive users. For sophisticated individuals, higher impatience leads to lower debt paydown. Naive agents often do not adhere to their paydown plans irrespective of their degree of impatience. This behavior is consistent with the notion that these households repeatedly delay debt paydown. We thus empirically validate our theoretical methodology for classifying users into sophisticated versus naive. Furthermore, our findings for both types of consumers suggest that both features of an individual's present bias - her level of short-run impatience

\footnotetext{
${ }^{1}$ Other papers have documented the sensitivity of consumption to the receipt of a paycheck (e.g., Zhang, 2017; Baugh et al., 2017; Shapiro, 2005; Stephens, 2006; Hastings and Washington, 2010; Gelman et al., 2014; Olafsson and Pagel, 2016) or other expected payments (e.g., Souleles, 1999; Browning and Collado, 2001; Hsieh, 2003; Parker, 1999; Scholnick, 2013; Baugh, Ben-David and Park, 2014). In a field experiment, Kaur, Kremer and Mullainathan (2010) randomize when workers are paid and find evidence for self control problems with respect to work effort. Jappelli and Pistaferri (2010) survey this literature on consumption responses to income changes.
} 
as well as her sophistication - are key factors in explaining her debt repayment behavior.

In general, it is hard to detect time-inconsistent behavior because an agent's initial intent and preferences are unobserved. Our ability to measure success in debt paydown relative to each individual's intent strengthens the interpretation of failure to reduce debt levels as an actual deviation from planned behavior, rather than an ex-ante optimal behavior given unobserved factors. The ability to follow through with their plans is a key theoretical distinction between sophisticated and naive agents. Empirically confirming this behavior difference validates not only our theoretical measure of sophistication, but also reinforces the importance of distinguishing between the two types when studying the effect of present bias, either theoretically or empirically. Finally, the large differences in following through with their paydown plans between those users classified as naive and those classified as sophisticated is one of the strongest pieces of evidence in favor of interpreting our results as evidence for present bias since no alternative explanation would predict this relationship with our measure of sophistication.

We consider a number of alternative explanations for both the individual consumption sensitivity to paycheck receipt, and the observed debt repayment behavior. While some possible explanations might be consistent with either one of the observed patterns, no competing explanation can explain the joint behavior of consumption and debt repayment observed in the data. For example, some people might have developed a habit of going out for "date night" every two weeks. This behavior might, by chance, overlap with the receipt of their paycheck in a way that is unrelated to short-run impatience. However, if such behavior was driving observed consumption responses to paycheck receipt, one would not expect these agents to also have differential debt repayment behavior. We discuss that for similar reasons, the following factors also fail to explain the joint patterns of consumption spending behavior and debt paydown: Non-separabilities in consumption or social coordination of consumption spending, time consistent preferences with high discount factors, loss of income, differences in the interpretation of what a plan means (e.g., aspirational versus realistic planning), overoptimism, a lack of planning skills, and financial literacy. The empirical results are also robust to different approaches to filtering out confounding factors, such as credit constraints and variations in measuring short-run impatience and sophistication. Specifically, we show that the consumption patterns used to measure short-run impatience and sophistication do not affect debt paydown other than through present bias. When estimating the sensitivity of consumption spending to paycheck receipt, our measure of shortrun impatience, the results are robust to varying the number of days of spending required for sample inclusion and to alternative specifications, such as using debit card spending only or using levels or weekly spending instead of daily log spending. Finally, as predicted by present bias, differences in behavior between sophisticated and naive users are driven by those with substantial levels of impatience, and excluding users who are noisily classified strengthens the results. We also illustrate the difference between using IV estimates, our preferred specification, rather than OLS estimates, to classify users as sophisticated or naive.

Several papers have explored the role of present-biased preferences in explaining a wide range of financial and non-financial decisions. They show that models with present-biased agents, or quasihyperbolic discounting as in Laibson (1997), can often rationalize the data better than models with standard agents. For instance, Laibson, Repetto and Tobacman (2007) estimate a life-cycle model 
with liquid and illiquid wealth, and find that the simultaneous holdings of both types of assets can be explained by a model with present bias. Shui and Ausubel (2005) show that present bias can explain consumer choices between different credit card offers. ${ }^{2}$ Meier and Sprenger (2010) conduct experiments to measure consumer impatience and find that more present-biased individuals have higher levels of credit card debt. Ashraf, Karlan and Yin (2006) elicit time preferences via a survey, and find that consumers with a lower discount rate were more likely to use a savings commitment product offered. ${ }^{3}$

The current paper complements this literature by showing that cross-sectional variation in repayment behavior corresponds to cross-sectional differences in measured short-run impatience and sophistication. Rather than determining impatience experimentally or through a survey, we infer the extent of short-run impatience directly from individuals' observed, real-life consumption behavior. As a major contribution, we propose a methodology to infer whether a person is aware of their shortrun impatience. This is something previous papers have not been able to measure. Specifically, the previous literature has identified sophisticated individuals as those who use costly commitment devices. However, this does not allow estimating the effect of sophistication since commitment devices directly affect outcomes. Moreover, the unique information on planned behavior also allows us to validate our measure by showing that it is associated with following through with originally-made plans - the key difference in the behavior of sophisticated and naive agents. Since high-frequency data on spending patterns is becoming more commonly available, the inference of a user's level of impatience and sophistication from consumption patterns can also be applied in other empirical settings. ${ }^{4}$

The paper continues as follows: Section 1 describes the data and presents summary statistics. Section 2 shows planned and actual paydown of users in our sample. Section 3 formally proposes empirical tests for both short-run impatience and sophistication and validates those in simulated data. Section 4 implements the empirical tests and Section 5 presents and validates our measures of impatience and sophistication with actual debt paydown patterns. Section 6 discusses alternative explanations and provides robustness checks and Section 7 concludes.

\section{Data}

\subsection{Empirical Setting}

The data are obtained from the online financial management service ReadyForZero (www.readyforzero.com), which offers users free help in managing their debt. ${ }^{5}$ When customers sign up, they are prompted to make a plan of how much they want to reduce their debt each month, and are encouraged to link their

\footnotetext{
${ }^{2}$ Skiba and Tobacman (2008) find that the behavior of payday loan borrowers is better captured by the hyperbolic model than the standard model. Paserman (2008), Fang and Silverman (2009) and Fang and Wang (2015) use similar approaches to show the effect of present bias on job searches, welfare program participation and mammogram usage.

${ }^{3}$ Several other papers have documented the influence of present bias based on consumer's choices between different contracting options. For instance, Madrian and Shea (2001), Choi et al. (2004) and Carroll et al. (2009) document the importance of default options in 401(k) savings plans, which can be attributed to the tendency of present-biased consumers to procrastinate. Present-biased preferences have also been shown to explain consumers' decisions regarding workouts (DellaVigna and Malmendier, 2006) or homework assignments (Ariely and Wertenbroch, 2002). DellaVigna (2009) provides an overview of the empirical evidence.

${ }^{4}$ Gelman et al. (2014), Baugh, Ben-David and Park (2014), Baker (forthcoming), and Olafsson and Pagel (2016) use similar datasets from different data providers.

${ }^{5}$ At the time of our sample, ReadyForZero was entirely free and private equity funded.
} 
bank accounts and credit cards, which grants the company read access. For each account, the data include daily snapshots of the balance, credit limit and transactions. The transaction data show the amount, date charged and description the customer sees on his bank account statement, as well as a code from the data provider which classifies transactions into different categories. The main service offered by the website is to allow users to see all their financial accounts in one interface, making it easier to keep track of different accounts and to help with calculating how to split a monthly payment between these different accounts (hence, the prompt to make a plan of how much to pay each month). These services can presumably appeal to a variety of households, irrespective of impatience or sophistication. It is therefore likely that these websites attract users who vary in terms of these characteristics. Moreover, some of the services offered could potentially serve as commitment devices by increasing the psychological cost of deviating from planned consumption. However, the website does not actually restrict user behavior in any binding way.

\subsection{Sample Selection}

We focus on those individuals who (i) have linked their checking account, (ii) receive regular biweekly paychecks, and (iii) appear to have linked all their active credit card accounts. This excludes a substantial fraction of users, most of whom have only linked their credit card accounts. We further restrict the sample to those users whom we observe for at least 180 days after sign-up. Since the users in our sample signed up for ReadyForZero, they cannot be considered representative of the overall population. However, they are uniquely suited to study why some individuals, despite their intentions, fail to repay substantial amounts of debt. The final sample includes a total of 516 users who fulfilled these criteria between September 2009 and September 2012. Appendix C.1 describes the sample selection in detail. To identify those with regular paychecks, we first isolate transactions which are likely paychecks, as outlined in Appendix C.2. A user receives regular bi-weekly paychecks if he receives paychecks of similar amounts about every two weeks (13 to 16 days apart) and at most one paycheck is missed. ${ }^{6}$ To be included in the sample, regular paychecks are also required to account for at least $70 \%$ of a user's income. This corresponds to an average of $68 \%$ of household income being made up by wages in the 2010 Survey of Consumer Finance (Ackerman, Fries and Windle, 2012). We further restrict the sample to users for whom spending over time appears to be primarily financed by the observed income and changes in assets. This approach excludes users who most likely have additional sources of income that we do not observe, such as users with accounts that are not linked. We also exclude users who have only recently linked all their accounts such that at early times in the sample, observed spending or debt balances are known to be incomplete. Finally, we require users to have at least eight qualifying pay cycles with at least 45 days of spending on consumption goods (as defined below) to allow us to estimate individual level impatience and sophistication.

\subsection{Income, Assets and Debt Paydown}

The first panel of Table 1 shows that the median user is observed in the sample for over one year (430 days). During this time, the average user receives 28 paychecks, of which 21 are regular pay cycles during which the paycheck arrives on time and no additional payment is received in the same

\footnotetext{
${ }^{6} \mathrm{~A}$ user can be an individual or a household. Households are included when the overall household income follows a biweekly paycheck pattern. Both households and individuals are excluded when they receive multiple substantial paychecks that do not follow a bi-weekly pattern.
} 
pay cycle. During regular pay cycles, the average user receives $\$ 3,778$ per month; the median user receives $\$ 3,460$. These monthly incomes are comparable to those in the 2010 Survey of Consumer Finance. ${ }^{7}$ The average credit card debt at sign-up is $\$ 13,808$, or almost four times the user's average monthly income. ${ }^{8}$ Data on interest rates is only available for a subset of accounts. Consumers face an average APR of $16.7 \%$ on their credit card accounts. On their bank account, users have an average cash balance of $\$ 4,822$ and a median cash balance of $\$ 2,099$, equivalent to $64 \%$ of average monthly income. ${ }^{9}$ Users also have substantial borrowing capacity left on their cards, $\$ 10,722$ on average. There is significant heterogeneity across users in debt levels, both in absolute and in relative terms. The $25^{\text {th }}$ percentile's debt level is $140 \%$ of monthly income, while the $75^{\text {th }}$ percentile has almost five times as much debt as monthly income.

\subsection{Spending}

We measure spending by examining all purchases made with credit or checking cards. Each transaction is already classified into one of about 50 different spending categories, such as restaurant meals, groceries or utilities. We also observe cash withdrawals. We distinguish between three different kinds of expenditures: regular payments, discretionary spending and spending that qualifies as neither. Appendix C.2 describes the classification in detail. Regular payments primarily include rent, mortgage and loan interest payments, but also smaller expenses such as magazine subscriptions. ${ }^{10}$ Non-regular payments are classified as discretionary or non-discretionary based on the category assigned by the data provider. Discretionary expenditures are those for which the consumer had a choice of whether to incur the expense close to when it had to be paid or had discretion over how much to spend. Nondiscretionary expenses are those for which the amount due depends on the accumulated behavior of the consumers in the past, but the consumer has no discretion on how much to pay once the bill arrives. Non-discretionary expenses primarily include utility or cell phone bills and similar expenses. Since consumption is not observed in the data, we proxy for consumption with expenditures likely to be consumed immediately or shortly after purchase. Specifically, we focus on short-run consumables, such as restaurant meals, groceries, gas and entertainment, as well as exclusively restaurant and entertainment expenditures. ${ }^{11}$

Table 2 shows summary statistics of users' monthly expenditures. Total monthly discretionary spending is about $\$ 1,800$ for the average user, which corresponds to about $52 \%$ of the user's regular income. 30\% of discretionary spending, $\$ 548$, is spent on short-run consumables, of which $\$ 290$ go to restaurant meals and entertainment. ${ }^{12}$ Regular monthly payments average $\$ 1,205$ per month, equivalent to $33 \%$ of users' regular income. Median monthly spending is slightly lower in all categories, but

\footnotetext{
${ }^{7}$ In the 2010 Survey of Consumer Finance (SCF), Ackerman, Fries and Windle (2012) find a median annual household income of $\$ 45,800$ and average income of $\$ 78,500$, of which roughly $70 \%$ are wages. Annual median wage income is about $\$ 42,000(12 * 3,460)$ so users in our sample earn more in wages than the median $\left(\$ 42,000\right.$ versus $\left.\$ 45,800^{*} .7=32,000\right)$, but less than the average $(\$ 45,336=12 * 3,778$ versus $\$ 78,500 * .7=\$ 55,000)$ household in the SCF.

${ }^{8}$ Therefore, average debt is slightly higher than the $\$ 12,900$ carried by households with revolving balances in the 2010 Survey of Consumer Finances (see Ackerman, Fries and Windle (2012)).

${ }^{9}$ In the 2010 Survey of Consumer Finances, we find average bank account cash balances of $\$ 4,520$ and a median on $\$ 1,326$.

${ }^{10} \mathrm{~A}$ set of transactions is classified as regular if the payments are about equal to each other and the payments are mostly 7,14 or 30 days apart and not more than one payment was missed.

${ }^{11}$ The Online Appendix lists the types of expenditures included in each of these categories.

${ }^{12}$ In the 2010 Survey of Consumer Finances, we find average food spending of $\$ 492$ and a median of $\$ 478$, with an average of $\$ 148$ and a median of $\$ 95$ on restaurants.
} 
shows similar patterns.

\section{Planned and Actual Paydown}

The unique feature of our data is the information on planned paydown. When users sign up for an account at ReadyForZero, they are prompted to state how much they want to reduce their debt each month. Based on this information, users receive payment reminders and the website helps them calculate how to split this monthly payment between the user's different accounts.

Table 3 shows that the average user plans to reduce their debt by $\$ 847$ per month, which corresponds to $12 \%$ of debt balances and to $24 \%$ of the user's monthly income. The median of planned paydown is lower at $\$ 598$, corresponding to $6 \%$ of debt levels and $18 \%$ of monthly income. Given these plans, the average user aims to reduce their current debt level by almost $30 \%$ over the next three months and by almost half over the next 6 months.

Next, we estimate which users characteristics affect planned paydown in a regression framework. The first set of columns of Table 4 show the results. Planned paydown is strongly related to income and original debt levels. For each dollar of additional income users plan to spend between 30 and 40 cents on debt reduction. Original debt levels also increase planned paydown but not by much: an increase of $\$ 100$ in debt is associated with $\$ 2.50$ of higher planned paydown each month. Cash balances, remaining available credit, total credit, discretionary spending, the interest rate paid, and the number of credit cards owned have no significant effect on planned paydown. However, users who use their credit cards more plan to pay more on debt reduction each month.

Compared to planned paydown, actual changes in debt levels are much lower. After 3 months, the average user has reduced debt levels by only $\$ 711$ according to Table 3 - on average, a shortfall of $\$ 1,732$, or $77 \%$ relative to the originally planned amount. A substantial fraction of users even increase their debt levels, as reflected in the increase in debt of $\$ 292$ for the $75^{\text {th }}$ percentile of changes in debt levels. While consumers do not reduce their debt levels much relative to their original plans, most make substantial payments on their credit cards. However, additional spending usually offsets the payments made. The second set of columns of Table 4 shows regression estimates of the relationship between planned and actual paydown controlling for user characteristics. For each dollar in planned paydown, the average user pays down between 25 and 30 cents. While most users therefore fall substantially short of their plans, originally planned paydown is still the single most predictive factor for actual paydown. Controlling for planned paydown, the user's income, debt levels, cash balances, available credit, total credit, interests rates or spending behavior do not significantly affect actual debt reduction. This indicates that planned paydown contains additional information about the user's ability to reduce debt not captured by income or spending, such as spending needs or the ease of reducing spending.

Overall, the results show that while plans are predictive of actual paydown, many users have substantial problems following their plans to reduce credit card debt. Not following through with originally made plans is a key prediction of present bias. The remainder of the paper analyzes to what extent present bias can indeed explain the observed failure of sticking with debt paydown plans. 


\section{Inferring Present Bias from Consumption Patterns}

This section theoretically shows how present bias and sophistication manifest in consumption patterns and proposes new empirical tests for both. We use simulated model data to validate our proposed empirical measures theoretically before using them to analyze their effect on debt paydown.

\subsection{Preferences}

The first empirical observation, that individuals do not follow through with their debt paydown plans, can be explained by a broadly applied preference specification: present bias or quasi-hyperbolic preferences, a modeling approach popularized by Laibson (1997). Each period $t \in\{0, \ldots, T\}$, a presentbiased agent with quasi-hyperbolic preferences discounts consumption utility in period $t+\tau, u\left(C_{t+\tau}\right)$ by $\beta \delta^{\tau}$, where $\beta \in[0,1]$ and $\delta \in[0,1]$. In turn, the agent maximizes his lifetime utility given by

$$
u\left(C_{t}\right)+\beta E_{t}\left[\sum_{\tau=1}^{T-t} \delta^{\tau} u\left(C_{t+\tau}\right)\right]
$$

The agent's discount factor between any two periods is not constant over time. Between any two consecutive future periods, the agent discounts by $\delta$. But between the current and all future periods, the agent is more impatient and applies an additional discount factor of $\beta$. If $\beta<1$, the agent is more impatient in the short-run relative to his long-run preferences. $\hat{\beta}$ denotes the agent's expectation of his future impatience factor $\beta$. We focus on three cases. (1) A sophisticated agent is perfectly aware of his short-run impatience, i.e. $\hat{\beta}=\beta$. (2) A naive agent believes that his future preferences will be identical to his current preferences, not realizing that his future self will become impatient, i.e., $\hat{\beta}=1$. (3) A standard agent discounts exponentially and thus behaves time consistently, i.e., $\hat{\beta}=\beta=1$. For simplicity, we assume a power-utility specification $u(C)=\frac{C^{1-\theta}}{1-\theta}$ for the agent's period utility function. In the context of our model, the agent's plan is her own expectation of future consumption. Hence, for sophisticated and standard agents, planned and actual future consumption will be the same. A naive agent's planned consumption is her consumption under the mistaken assumption that her future impatience factor will be equal to 1 , i.e., under her belief $\hat{\beta}=1$. The consumption plan then determines the debt paydown plan we observe empirically.

\subsection{Model Environment}

All agents face a simple budget constraint. Cash-on-hand $X_{t}$ is determined by their initial consumption $C_{t-1}$ and savings $A_{t-1}$ as well as their income $Y_{t}$ and the opportunity to save, at interest rate $R^{s}$, or borrow, at interest rate $R^{b}$, summarized by the function $R\left(A_{t-1}\right):=R$, i.e.,

$$
X_{t}=A_{t-1} R+Y_{t}=\left(X_{t-1}-C_{t-1}\right) R+Y_{t}
$$

Income in each period $Y_{t}$ is characterized by a permanent component $P_{t}$ that grows deterministically each period by $G_{t}$. Moreover, income is characterized by transitory shocks $N_{t}^{T}$, i.e.,

$$
Y_{t}=P_{t} N_{t}^{T}=P_{t-1} G_{t} N_{t}^{T}
$$


The transitory shocks allow for a low probability $p$ of unemployment or illness

$$
N_{t}^{T}=\left\{\begin{array}{cc}
e^{s_{t}^{T}} & \text { with probability } 1-p \text { and } s_{t}^{T} \sim N\left(\mu_{T}, \sigma_{T}^{2}\right) \\
0 & \text { with probability } p
\end{array}\right\} .
$$

From period $t=$ Ret on, the agent retires and earns his permanent income without uncertainty. We omit permanent income shocks because in our empirical setting, we select individuals with stable employment and income over the sample period and are interested in inferring features of present bias from individual reactions to transitory income fluctuations. Moreover, Carroll (2001) among others argues that household income processes are well approximated by a deterministic trend and a transitory shock. Furthermore, we assume the absence of credit constraints because we exclude users who have low liquidity in the empirical analysis.

\subsection{Model Equilibrium}

We can obtain the equilibrium solution by backward induction. For the standard and sophisticated agent, we derive the equilibrium consumption function under the premise that the agent enters period $t$, optimizes over consumption, and expects to behave in the same manner in the future. This equilibrium concept corresponds to the solution of Laibson (1997). The naive agent, however, enters period $t$, optimizes over consumption, but expects to behave in a different manner in the future. In fact, because $\hat{\beta}=1$, the naive agent expects his future self to discount payoffs only by $\delta^{\tau}$ instead of by $\beta \delta^{\tau}$. Assuming a power-utility specification precludes an analytical solution, but simulations using numerical backward induction suggest that a unique equilibrium exists. ${ }^{13}$

\subsection{Calibration and Consumption Life-cycle Profiles}

We calibrate the environmental and preference parameters in line with the literature. All parameters are displayed in Table 5. For the income process we follow the fairly tight ranges suggested in the life-cycle literature such as Gourinchas and Parker (2002). Specifically, $\mu_{T}=0, \sigma_{T}=0.8$, and $p=$ $0.1 \% .{ }^{14} G_{t}$ is assumed to follow a hump-shaped income profile that we estimate from the Consumer Expenditure Survey (CEX) using a standard pseudo-panel approach. Moreover, because Gourinchas and Parker (2002) choose 25 years as the beginning of life, we choose the retirement period Ret $=11$ years and the life span $T-$ Ret $=54$ years, in accordance with the average US retirement age according to the OECD, and the average US life expectancy according to the UN. At age 25, we set the mean ratio of liquid wealth to income equal to one, $A_{0} / P_{0}=1$. The mean of Moody's municipal bond index is $3.1 \%$ such that $R^{s}=1.031$ and, as in our data, the interest on borrowing is $R^{b}=1.167$. We assume the exponential discount factor to be $\delta=0.94$ and the coefficient of risk aversion to be $\theta=2$, both standard choices in the literature. Empirical estimates for the present-biased parameter typically range from around $\beta=0.6$ to $\beta=0.9$ (see Angeletos et al. (2001) among others) when the exponential

\footnotetext{
${ }^{13}$ The consumption functions are increasing and concave and the equilibrium appears easy to solve for and stable. Carroll (2011) and Harris and Laibson (2002) demonstrate the existence and uniqueness of equilibria for the standard and sophisticated hyperbolic-discounting agents in similar environments.

${ }^{14}$ We choose a relatively high volatility for the transitory income shocks for the following reason: when we simulate the model at a bi-monthly frequency to match our empirical setting, we need a minimum amount of variation that equals $0.8 \sqrt{1 / 24}$ for an annualized volatility of 0.8 . To compensate, we set the permanent income shock to zero and also assume a relatively low probability of unemployment or illness $p$.
} 
discount factor is around one $(\delta=0.94)$. We will show how varying values of $\beta$ affect the estimates and how we can use consumption patterns to infer $\beta$ empirically. For the following illustration, we set $\beta=0.7$. We first simulate the model at an annual frequency, as is standard in the literature, then move on to a bi-monthly frequency in line with our empirical setting. We initially explore the model at a lower frequency to see how far we could differentiate sophistication versus naivete using standard data sources, such as the CEX.

Figure 1 contrasts the consumption paths of the three types of agents considered - standard, naive present-biased, and sophisticated present-biased - with the empirical consumption and income profiles estimated from CEX data. Consistent with the data, sophisticated present-biased and naive present-biased preferences generate a hump-shaped consumption profile. Moreover, power utility implies prudence, such that all agents have a standard precautionary-savings motive causing an initially increasing consumption path. But, the present-biased agents are also sufficiently impatient, such that consumption eventually decreases. Overall, we conclude that the calibrated lifetime consumption profiles look reasonably similar to the average consumption profile from CEX data rendering our calibration appropriate. However, the more important takeaway is the following: sophistication versus naivete does not make a big difference with respect to the shape of the consumption profile. Thus, we cannot use standard data sources to tell whether individuals are sophisticated or naive. As we will show later, however, sophisticated versus naive individuals differ substantially in their highfrequency responses to income payments when they have low versus high resources and in following through with their credit card debt paydown plans. Our high-frequency data on spending, resources, and plans thus allows us to determine whether individuals are sophisticated or naive and how far this affects their actual versus planned debt paydown.

\subsection{Euler Equations and Intuition for Empirical Measures}

Tobacman (2007) shows that the Euler equations for the standard, sophisticated present-biased, and naive present-biased agents can be expressed as follows:

$$
u^{\prime}\left(C_{t}\right)=\delta E_{t}\left[R\left(\beta \frac{\partial \hat{C}_{t+1}}{\partial X_{t+1}}+\frac{\beta}{\hat{\beta}}\left(1-\frac{\partial \hat{C}_{t+1}}{\partial X_{t+1}}\right)\right) u^{\prime}\left(\hat{C}_{t+1}\right)\right]
$$

with $\hat{C}_{t+1}$ being planned consumption in $t+1$, which equals actual consumption for the standard and sophisticated but not the naive agent. This specification nests the standard agent's Euler equation, i.e., $\beta=\hat{\beta}=1$,

$$
u^{\prime}\left(C_{t}\right)=\delta E_{t}\left[R u^{\prime}\left(C_{t+1}\right)\right]
$$

Comparing the Euler equations illustrates the intuition for our proposed measures of an individual's present bias, captured by his short-run impatience, $\beta$, and whether the individual is sophisticated or naive about their future impatience. When deciding on how much to consume in the current period relative to future periods, present-biased agents are overly impatient in the short run. Hence, we would expect a higher marginal propensity to consume out of transitory income for present-biased agents and for this response to be stronger the more impatient the agent is in the short run (the smaller $\beta$ is).

Differences between sophisticated and naive agents arise when individuals' current choices de- 
pend on their beliefs about their future choices, such as when they consider passing on resources to their future selves. The fully naive present-biased Euler equation, i.e., $\hat{\beta}=1$ and $\beta<1$, is

$$
u^{\prime}\left(C_{t}\right)=\delta E_{t}\left[R \beta u^{\prime}\left(\hat{C}_{t+1}\right)\right]
$$

A naive agent does not anticipate being overly impatient in the future. Instead, he believes his future selves will share his current self's (relatively patient) long-run preferences and choose consumption accordingly, i.e., $\hat{\beta}=1>\beta$. The naive agent therefore chooses current consumption such that the ratio of present to future marginal utility is equal to the discount factor between the two periods. He expects his future self to follow through with this plan as the standard agent would.

In contrast, the sophisticated present-biased Euler equation, i.e., $\beta=\hat{\beta}<1$, is

$$
u^{\prime}\left(C_{t}\right)=\delta E_{t}\left[R\left(\beta \frac{\partial C_{t+1}}{\partial X_{t+1}}+\left(1-\frac{\partial C_{t+1}}{\partial X_{t+1}}\right)\right) u^{\prime}\left(C_{t+1}\right)\right]
$$

Unlike naive agents, sophisticated agents know that their future selves do not share their more patient long-run preferences, and will again be overly impatient. They know that a smaller fraction of future resources will be saved by the future self than the current self would like. Because the future selves will not smooth consumption to maximize utility, as for the standard agent (or as believed by the naive agent), saving becomes somewhat more valuable. How much the future self consumes rather than saves depends on the level of available resources. When resources are higher, the declining marginal utility of consumption leads future selves to consume a smaller share of any marginal resources passed on to them. Hence, future selves act more in the interest of the first period's self. Aware of this reduced conflict in future resource allocation, the current self is more willing to pass on additional resources to his future selves. In the Euler equation, this mechanism is captured by the effective discount factor, $\left(\beta \delta \frac{\partial C_{t+1}}{\partial X_{t+1}}+\delta\left(1-\frac{\partial C_{t+1}}{\partial X_{t+1}}\right)\right)$. As the marginal propensity to consume out of resources in the next period, $\frac{\partial C_{t+1}}{\partial X_{t+1}}$, decreases, the current period self acts more patiently, since there is more weight put on the long-run discount factor, $\delta$, relative to the short-run discount factor $\beta \delta$. With diminishing marginal utility of consumption, the marginal propensity to consume decreases with the level of resources. Hence, we would expect sophisticated agents to act more patiently when they expect next period's resources to be high and marginal utility to be low. This mechanism does not exist for naive agents, however, who are unaware of a potential conflict of interest with their future selves. This difference allows us to distinguish between naive and sophisticated present-biased agents.

\subsection{Measuring Short-Run Impatience}

To make the following simulation exercises comparable to our empirical setting, we simulate the model and run the regressions at a bi-monthly instead of annual frequency. Moreover, we ensure our empirical setting has sufficient statistical power by assuming the same number of agents - 516 and the same number of bi-monthly paychecks - 26 (the median number of payweeks for users in our sample).

The annualized parameters, such as the exponential discount factor, are the same as in the previous model and displayed in Table 5, but a simulated period is now shorter to match our empirical 
setting. ${ }^{15}$

Based on the Euler equation above, we would expect that present-biased agents who are more impatient in the short run (lower $\beta$ ) have a higher marginal propensity to consume (MPC) out of transitory income fluctuations. We estimate the following standard log consumption growth or MPC regression following Campbell and Deaton (1989), among many others, using simulated data of the agents in our model:

$$
\Delta \log \left(C_{t+1}\right)=a+b_{1} \Delta \log \left(Y_{t+1}\right)+e_{t+1} .
$$

Table 6 shows the resulting estimates for $b_{1}$ and standard errors for a range of short-run impatience $\beta$. For agents who are more impatient in the short run (lower $\beta$ ), we indeed estimate higher MPC coefficients $b_{1}$ as they react more strongly to changes in income from period to period. ${ }^{16}$ Moreover, we can see that the difference between the sophisticated and naive agents' MPCs become larger for greater levels of short-run impatience or present bias. The reason is that the sophisticated agent understands that his future value is greatly reduced by his future present bias. That makes saving somewhat more valuable and decreases the sophisticated agent's MPC relative to the naive agent's at greater levels of short-run impatience.

\subsection{Measuring Sophistication}

The Euler equation above suggests that sophisticated agents act more patiently when they expect a lower marginal propensity to consume in the next period. Thus, there appears a relationship between consumption growth $\Delta C_{t+1}$, income growth $\Delta Y_{t+1}$, and the inverse of the marginal propensity to consume $1-M P C_{t+1}=1-\frac{\partial C_{t+1}}{\partial X_{t+1}}$. In turn, we can estimate a modified consumption growth regression with income growth and the inverse of the marginal propensity to consume interacted with income growth:

$$
\Delta \log \left(C_{t+1}\right)=a+b_{1} \Delta \log \left(Y_{t+1}\right)+b_{3}\left(1-M P C_{t+1}\right) \Delta \log \left(Y_{t+1}\right)+e_{t+1} .
$$

We expect $b_{3}$ to be negative for the sophisticated agent, but not for the naive agent. Table 7 shows the results. In line with our intuition, we find negative and significant estimates of $b_{3}$ for the sophisticated but not for the standard or naive agents.

While we can infer the marginal propensity to consume theoretically in the model, in the data, marginal propensities to consume are unobservable and need to be estimated from observables. We propose the level of resources available to the individual from the last period (outgoing savings, $A_{t+1}$, normalized by maximum savings over the sample period $A_{\text {max }}$ to obtain a number comparable to the MPC in variation) as a proxy for the marginal propensity to consume. ${ }^{17}$ With diminishing marginal utility of consumption, higher resources lead to a lower marginal propensity to consume. Further-

\footnotetext{
${ }^{15}$ We solve for the infinite-horizon model as bi-monthly periods are very short. Here, because the income profile estimated from CEX data is hump-shaped, we assume a constant growth rate of $3 \%$ to simulate agents early to mid-life in their lifecycle where they would borrow more. $3 \%$ is the average growth rate of the income profile estimated from CEX data at ages 25 to 55. The results are not different if instead we would simulate data at a quarterly or annual period assuming the calibration in Table 5 or similar parameter values that are standard in the literature. Furthermore, results are not affected when we assume a finite horizon and take a random sample of agents' ages and initial savings levels to simulate the data.

${ }^{16}$ Even for the standard agent the baseline MPC is relatively high because we assume an income growth rate of $3 \%$ to simulate agents early to mid-life in their life-cycles.

${ }^{17}$ In the empirical exercise, we use balances, thus income minus consumption, which equals outgoing savings, i.e., $A_{t+1}=$ $X_{t+1}-C_{t+1}$.
} 
more, to align our theoretical model with our empirical approach, we do not use logged consumption growth, but logged absolute consumption as the outcome variable and logged absolute income as the explanatory variable. Thus, we validate our empirical approach in the simulated data by estimating the following regression:

$$
\log \left(C_{t+1}\right)=\alpha+b_{1} \log \left(Y_{t+1}\right)+b_{2} \frac{A_{t+1}}{A_{\max }}+b_{3} \frac{A_{t+1}}{A_{\max }} \log \left(Y_{t+1}\right)+\varepsilon_{t+1} .
$$

Table 8 shows the results. Again we find a negative coefficient $b_{3}$ for sophisticated agents but not for naive ones. This is in line with our intuition and thus providing a valid empirical test for sophistication.

\section{Consumption Patterns}

This section estimates each user's sensitivity to paycheck receipt and how it is affected by varying resources over time by implementing the empirical tests we just validated theoretically. After estimating each user's level of short-run impatience and sophistication, we can relate those to debt paydown behavior in the next section.

\subsection{Sensitivity of Consumption to Paycheck Receipt}

\subsubsection{Regression Equation}

The average sensitivity of consumption spending to paycheck receipt for user $i$ is estimated in the following equation:

$$
\log \left(E_{i t}\right)=\alpha_{i}+\text { payweek }_{i t} \gamma_{1 i}+X_{i t} \psi_{i}+\varepsilon_{i t}
$$

$E_{i t}$ are user $i$ 's consumption expenditures on day $t$. paywee $k_{i t}$ is an indicator equal to 1 on the day of paycheck receipt and the 6 subsequent days and 0 on all remaining days. $X_{i t}$ includes month fixed effects and day-of-week fixed effects. Estimating equation (4) separately for each user yields a user-specific estimate of sensitivity of consumption spending to paycheck receipt, captured by the coefficient on payweek, $\gamma_{1 i}$.

We focus on expenditures $E_{i t}$ for goods likely to be consumed shortly after purchase, which we call short-run consumables ${ }^{18}$ : restaurant and entertainment expenditures and food and gas purchases. Since food and gas can be stored for a while rather than immediately consumed, we also present results for just restaurant and entertainment spending and show that the consumption patterns look very similar.

\subsubsection{Filtering Out Credit Constraints}

We are interested in capturing the extent of sensitivity to paycheck receipt that reflects a user's level of short-run impatience. But, if expense shocks come at times when consumers are credit constrained, they also lead to increased spending in payweeks. To isolate the effect of short-run impatience, we

\footnotetext{
${ }^{18}$ Measuring consumption by expenditures can lead to misleading conclusions, as shown by Aguiar and Hurst (2005). We focus on expenditure categories that are likely to be a good proxy for actual consumption, such as restaurant meals and entertainment. We also estimate spending patterns over several pay cycles in which consumers do not experience income shocks. It is therefore unlikely that the estimates are driven by shifts in behavior from one regime to another in response to shocks.
} 
thus restrict the sample to those paycycles in which short-run credit constraints are unlikely to play a role. Specifically, we restrict the sample to those times in which the user had enough resources (cash in his account and, especially, available credit on his cards) to afford the payweek's worth of spending in the previous week. In Section 6.4, we show that our results are also robust to more conservative measures of credit constraints.

\subsubsection{Estimated Sensitivity to Paycheck Receipt}

Table 9 shows estimates of the sensitivity $\gamma_{1 i}$ in our sample. On average, users indeed consume significantly more during payweeks than non-payweeks even if credit constraints are unlikely to play a role. During payweeks, spending on short-run consumables is $6.1 \%$ higher, and spending on restaurants and entertainment is $4.7 \%$ higher. There is substantial variation between users. For instance, at the $75^{\text {th }}$ percentile users increase consumption in both categories by almost $20 \%$ in payweeks. ${ }^{19}$ Some of this variation is due to noise in the estimation and some due to differences among individuals. We therefore bootstrap standard errors for all estimates below in which sensitivity to paycheck is used as an explanatory variable to account for the variation due to noise rather than actual differences between individual users. Bootstrapping the standard errors is the most conservative approach we can take and tends to yield higher standard errors than other approaches.

\subsection{Effect of Resources on Sensitivity to Paycheck Receipt}

\subsubsection{Regression Equation}

The effect of variation in resources on the sensitivity to paycheck receipt is estimated separately for each user by the following equation:

$$
\log \left(E_{i t}\right)=\alpha_{i}+\text { payweek }_{i t} \gamma_{1 i}+\text { resources }_{i t} \gamma_{2 i}+\text { resources }_{i t} * \text { payweek }_{i t} \gamma_{3 i}+X_{i t} \psi_{i}+\varepsilon_{i t}
$$

where, as in equation (4), $E_{i t}$ are each user's daily expenditures, payweek $k_{i t}$ is an indicator equal to 1 on the day of paycheck receipt and the 6 subsequent days and 0 on all remaining days, and $X_{i t}$ includes month fixed effects and day-of-week fixed effects. resources $i t$ are a user's available resources, defined as the cash balances on his bank accounts plus the available credit on his credit cards.

\subsubsection{Wealth Fluctuations due to Regular Payments}

To estimate the effect of varying resources, we exploit within-agent variation in resources over time. ${ }^{20}$ However, the level of resources available to the agent at every point in time is not exogenous to the agent's consumption decision. There are two sources of endogeneity. First, expenditures in the beginning of the pay cycle reduce the resources available later in the pay cycle one-for-one. This can be addressed by measuring resources at the beginning of each pay cycle. Second, resources in the

\footnotetext{
${ }^{19}$ Appendix Figure A1 plots the distribution of the estimated sensitivity for both categories of consumption. The two distributions look very similar and confirm the key insights of Table 9: The mean of the distributions is shifted upwards from zero, and a t-test confirms that it is significantly different from zero.

${ }^{20}$ In the literature, the effect of higher resources on the sensitivity of consumption is often estimated across individuals, for instance by Stephens (2006). Using within-individual variation instead provides an alternative estimate of the effect of resources.
} 
given pay cycle depend on past consumption. This is problematic if high prior spending not only reduces the agent's resources, but also his taste for consumption in the current period, leading to biased estimates. For instance, a user who went out regularly over the last weeks, going to the movies and eating out, has lower resources in the current pay cycle. Additionally, he may have a lower taste for new consumption, having seen the latest movies and been to his favorite restaurants.

To address this endogeneity problem, we exploit variation in the agent's resources due to regular payments. Users in our sample are paid twice a month, but have regular monthly expenses, such as rent or mortgage payments. These monthly obligations lead to substantially lower resources during the two-week pay cycle when they are due relative to the other two weeks of the month. Another example are months with three paychecks for users who are paid bi-weekly (rather than twice a month). We exploit the systematic fluctuations in the level of resources caused by such regular payments to construct an instrumental variable for the level of resources. Based on the agent's regular payments, we calculate what his resources would have been if all non-regular spending was split evenly across the sample period. These hypothetical balances isolate the variation caused by regular payments from the variation caused by prior discretionary spending. Figure A2 in Appendix A.2 illustrates the intuition for these calculated balances.

\subsubsection{Measuring Sophistication by Effect of Resources on Sensitivity}

We estimate how fluctuations in resources affect the sensitivity of consumption spending to paycheck receipt using the hypothetical balances based on regular payments as an instrumental variable The user-specific estimates captured by $\gamma_{3 i}$ in equation (5) are shown in the bottom panel of Table 9.

As outlined in Section 3, additional resources lead sophisticated agents - but not naive ones to act more patiently, and their consumption reacts less to payment receipt. We split the sample into two groups. Those for whom additional resources reduce sensitivity to paycheck receipt, i.e., $\gamma_{3 i}$ is negative, and those for whom this is not the case, i.e., $\gamma_{3 i}$ is non-negative. For the median user, the effect is close to zero in both short-run consumable spending and exclusively restaurant and entertainment spending. But there is substantial heterogeneity allowing us to split the sample along this characteristic.

Because differences in the effect of resources theoretically correspond to differences in sophistication, we call the first group "sophisticated" and the latter "naive". Note that we classify every user, including those with no or low levels of short-run impatience, as either sophisticated or naive. We address the fact that a classification into "sophisticated" and "naive" is not very meaningful for users who are time-consistent or close to time-consistent (as captured by low sensitivity to paycheck receipt) below in section 6.3. Table 10 shows the classification of users into sophisticated and naive. A substantial number of users are classified the same way, irrespective of whether the classification is based on spending on short-run consumables or on restaurant and entertainment only. However, for almost a third of users, the classification differs between the two categories. Therefore, we bootstrap standard errors whenever the estimates are used as explanatory variables in a regression and show that our results are similar using only consistently classified users in Appendix B.4. 


\subsubsection{Summary Statistics by Differences in Consumption Patterns}

One concern is that agents classified as sophisticated or naive also differ substantially along dimensions other than sophistication. Specifically, differences in sophistication may not only lead to differences in debt paydown behavior, but may also reflect differences in the level of impatience, assets, earnings or total spending.

Table 11 shows average and median estimated sensitivity levels for naive and sophisticated users based on short-run consumables and on restaurant and entertainment spending only. When based on short-run consumables spending, estimated levels of sensitivity to paycheck receipt are larger for sophisticated agents. When based on restaurant and entertainment spending only, they are lower, but the differences between the two groups is not statistically significant in either case.

There are several factors that could lead sensitivity estimates to differ between the two groups, though none seems to clearly dominate in our sample. First, average sensitivity estimates are biased slightly downwards for sophisticated agents. When resource levels are high, sensitivity is lower for a sophisticated agent than it is for a naive agent with the same level of impatience. Therefore average sensitivity, estimated for times of both low and high resource levels, will be lower for a sophisticated agent than for a naive one with the same level of impatience. ${ }^{21}$ A second factor is measurement error in classifying users into sophisticated and naive. If sensitivity of consumption to paycheck receipt is relatively low, sensitivity changes due to resource fluctuations are also small in absolute terms and, when measured with error, less likely to be detected. Sophisticated users with low levels of impatience therefore have a higher likelihood of being incorrectly classified as naive than users with high levels of impatience. In the robustness checks, in Section 6.3, we therefore exclude users with low sensitivity who are most likely to be misclassified. Third, the level of impatience may be directly related to whether a user is aware of his short-run impatience. Users with high short-run impatience may be more likely to eventually become aware of their own time inconsistency relative to users with a relatively minor time inconsistency problem.

In addition to estimated levels of sensitivity, Table 11 shows some key summary statistics on income and debt levels across naive and sophisticated users. Income and initial credit card debt levels are very similar between the two groups. Average income is almost identical. Average initial debt is slightly lower, $\$ 13,693$ relative to $\$ 14,144$, for sophisticated users, but median debt is higher for sophisticates. Table 11 also shows that sophisticated and naive agents have very similar spending habits across all categories, both in absolute terms and relative to their income. Both types also use their credit card in similar ways and charge $31 \%$ of total purchases on their credit cards. In general, the differences between sophisticated and naive agents in assets and spending are small and none is statistically significant. It is therefore unlikely that the classification into naive and sophisticated masks substantial differences between the two groups along other dimensions which could directly account for any differences in their debt repayment behavior. It is also consistent with the notion that the services provided by ReadyForZero appealed to a variety of users with credit card debt and did not target those with some form of present bias.

\footnotetext{
${ }^{21}$ Instead of using the average sensitivity to paycheck receipt estimated by equation (4), an alternative measure would be the base level of sensitivity captured by the coefficient on payweek in equation (5). However, because of the additional variables and the need to instrument for them, the estimates are much more noisy. Because of this higher precision, we use the average sensitivity in the regression analysis, since the focus is on intra-, not inter-, group comparisons.
} 
The fact that we do not find large differences in income, assets, or spending between sophisticated and naive users also lines up with our theoretical results that, in terms of the life-cycle profiles, as shown in Figure 1, sophisticated agents do not differ much from naive agents. ${ }^{22}$ This theoretical finding reinforces the need for an alternative measure of sophistication versus naivete like the one we propose.

Finally, we also do not find substantial differences in the levels of planned paydown. Appendix table A2 shows that the main determinants of planned paydown are income and original debt levels which are very similar across the two groups. There is no statistically significant effect of sensitivity or sophistication on planned paydown. Hence, planned paydown seems to be determined primarily by factors such as income, existing debt levels and possible other considerations such as spending needs and ease of reductions in spending. Thus, the next question is whether sophisticates are better in meeting their debt paydown plans.

\section{The Effect of Present Bias on Debt Repayment}

Section 4 showed that consumption patterns over the paycycle are consistent with users exhibiting short-run impatience and varying levels of sophistication. As outlined in section 3, this section uses these patterns as proxies for the extent of each user's present bias and relates them to their success in reducing debt levels.

\subsection{Nonparametric: Debt Paydown by Type}

Figure 2 shows the average change in debt levels over the first 90 days for both sophisticated and naive users by quintiles of their estimated sensitivity to paycheck receipt. In both groups, some users pay down substantial amounts of debt. Among sophisticated users, those in the two lowest quintiles of sensitivity to paycheck receipt reduce their debt levels the most. As sensitivity to paycheck increases, paydown falls. For naive users, no such pattern exists. However, the graph does not control for any characteristics of users, especially planned paydown, a key determinant of debt paydown. To do so, the next section shows regression analysis of the effect of sensitivity and planned paydown.

\subsection{Regression Equation}

To formally analyze the effect of potential present bias as captured by consumption patterns on debt paydown, we estimate the following regression:

$$
\begin{aligned}
\text { Paydown }_{i}=\mu_{0} & + \text { Sensitivity }_{i} \mu_{1 n}+\text { PlannedPaydown }_{i} \mu_{2 n} \\
& + \text { Sensitivity }_{i} * \text { Sophist }_{i} \mu_{1 s}+\text { PlannedPaydown }_{i} * \text { Sophist }_{i} \mu_{2 s} \\
& +X_{i}^{\prime} \lambda+v_{i}
\end{aligned}
$$

where Sensitivity ${ }_{i}$ is each user's sensitivity of spending to paycheck receipt, estimated by equation (4). PlannedPaydown $i$ is the amount the user originally had planned to pay down and Sophist ${ }_{i}$ is an indicator for whether the user is classified as sophisticated. $X_{i}$ is a set of control variables which include the user's monthly income and debt levels at sign up. We measure debt paydown over two

\footnotetext{
${ }^{22}$ Other papers such as Angeletos et al. (2001) also find only small differences in asset accumulation between sophisticated and naive agents.
} 
horizons: 90 and 180 days. To make estimates comparable, debt paydown and planned paydown are therefore measured per day. Debt paydown is measured by the trend in debt balances over the given time horizon. Relative to the simple difference in debt levels, this measure filters out fluctuations in debt levels caused by the use of credit cards for transactions. To measure the trend in debt levels, we fit a linear trend for the user's debt balances over the given horizon, such that average daily paydown equals the slope of the estimated trend line. ${ }^{23}$

\subsection{Regression Results}

Table 12 shows the regression estimates for equation (6) over time horizons of 90 and 180 days. Since the regressors "Sensitivity" and "Sophisticated" are themselves estimated from consumption patterns, standard errors in the second stage are bootstrapped to be most conservative. ${ }^{24}$ For naive agents, the omitted category, an additional dollar in planned paydown increases actual paydown by 18 cents over the first 90 days and by 13 cents over 180 days. In our baseline specification shown here, sensitivity has a positive effect on paydown which is statistically significant over the 180 day horizon, but this result is not robust across different specifications as shown throughout section 6 . We therefore interpret our results as ambiguous regarding the effect of short-run impatience for naive users' paydown.

For sophisticated users, planned paydown is substantially more predictive of actual paydown than for naive users. Specifically, the estimated effect in the first 90 days is 55 cents $(.18+.37)$ and 52 cents $(.13+.39)$ in the first 180 days. As shown below, these results are very similar and robust across different specifications. Unlike for naive users, the level of short-run impatience has a significant negative effect for sophisticated users. More impatient agents reduce their debt less. The difference relative to naive users, as well as the combined effect for sophisticates, is statistically significant (unreported test) and economically meaningful: moving from the $75^{\text {th }}$ to the $25^{\text {th }}$ percentile of estimated impatience levels increases debt paydown in the first 90 days after sign up by $\$ 623$. This is a substantial fraction of the average paydown of $\$ 711$ over this time horizon. ${ }^{25}$ There is no statistically significant difference in the effect of the control variables for sophisticated and naive users. In fact, most of the control variables have no substantial effect on actual paydown once planned paydown is included, consistent with the results presented in Table 4. The estimated relationship between the characteristics of a user's consumption patterns and his debt paydown reflects what one would expect if both were caused by present bias: Sophisticated users are better in following through with their debt paydown plans, but higher short-run impatience leads them to pay down less over a given time period. The results also reinforce the interpretation of sensitivity to paycheck receipt as a measure of impatience and validates the classification of users as naive or sophisticated. After all, better ability to follow plans is a key prediction of sophistication.

\footnotetext{
${ }^{23}$ In unreported robustness checks, we use the simple difference in debt levels and the results are very similar.

${ }^{24}$ For each user, we draw a bootstrap sample from the observations of consumption spending and re-estimate the first stage variables for each draw. Then we use these estimates in the second stage estimation and compute bootstrapped standard errors based on the second stage results of all draws. Using robust standard errors to interpret the results would not change the overall conclusions though it would increase statistical significance generally.

${ }^{25}$ The difference between the $25^{\text {th }}$ and $75^{\text {th }}$ percentile for the estimated sensitivity based on short-run consumables is $.28=.199+0.081$, as shown in Table 9. Multiplying the direct effect plus the difference for sophisticated agents by this difference yields an estimated effect of $\$ 6.93$ per day, or $\$ 623$ over 90 days.
} 


\section{Robustness and Alternative Interpretations}

Attributing the results in Section 5 to present bias and, hence, supporting our notion of using spending patterns to measure present bias, requires that the two are related only through a user's present bias and that no other factor is plausibly driving the results. This section shows robustness of our main results and shows that alternative explanations for some of the patterns in the data fail to explain the joint behavior of debt paydown and consumption patterns.

\subsection{Robustness of Estimating Effect on Paydown}

Estimates based Only on Restaurant and Entertainment Spending and Regression Specification Our main results in Table 12 use spending patterns based on short-run consumables as proxies for short-run impatience and sophistication. The first two columns of Appendix Table A3 use spending patterns based only on restaurant and entertainment spending instead. The results are very similar to our baseline results: The level of short-run impatience has a significant negative effect for sophisticated users, but not for naive users and planned paydown is substantially more predictive of actual paydown for sophisticated rather than naive users.

The remaining columns of Appendix Table A3 explore different regression specifications. Our baseline specification allows the effect of the control variables to differ between sophisticated and naive users. Appendix B.1 shows that the estimates are very similar when income and original debt levels are not interacted with sophistication and the control variables are restricted to have the same influence for both types of users. Another possible concern about the specification in equation (6) is that planned paydown and the estimated level of sensitivity to paycheck receipt are highly correlated. We, therefore, estimate separate specifications in which either the sensitivity to paycheck or planned paydown is interacted with sophistication, and the respective other variable is only included as a control (not interacted with sophistication). The results are very similar.

Direct Relationship between Paydown and Consumption Patterns One potential concern is that spending patterns are directly linked to debt paydown, not just through behavioral biases, since, by definition, debt paydown requires a reduction in consumption spending. First, there is no mechanical relationship between the spending patterns and debt paydown. The sensitivity to paycheck receipt, which is used to measure present bias, only captures how evenly consumption is split over the pay cycle. It is thus unrelated to the level of consumption, which is what affects debt paydown. This leaves enough variation to identify potential differences in the amount of debt paid down. In other words, sensitivity of consumption captures the ratio of future to present consumption $\left(\frac{C_{t+1}}{C_{t}}\right)$, but saving for debt paydown depends on the level of consumption spending ( saving $=$ income $-C_{t+1}-C_{t}$ ). Therefore agents can exhibit the same level of sensitivity to paycheck receipt, while having different levels of debt paydown. Similarly, agents with the same amount of debt reduction may choose to split the remaining resources differently between the two periods of the pay cycle, leading to different sensitivity of consumption spending, but equal debt reduction. ${ }^{26}$

\footnotetext{
${ }^{26}$ Consider the following example to illustrate this point: An agent with a paycheck of $\$ 100$ saves $\$ 50$ and consumes $\$ 30$ in the first period and $\$ 20$ in the second period, leading to $50 \%$ higher consumption in payweeks. Alternatively, the agent can consume $\$ 60$ in the first period and $\$ 40$ in the second, leading to the same sensitivity of consumption spending but different paydown. Similarly, saving $\$ 50$ but consuming $\$ 25$ each period leads to the same savings as in the first case, but
} 
Nevertheless, it could be the case that users who smooth consumption more when they have higher resources, which we label sophisticates, may also be those who consume a lower share of these additional resources, leading them to save more for debt paydown. A high reduction in sensitivity as resources increase (i.e., a more negative coefficient on the interaction of payweek $*$ resources) would lead to higher debt paydown. Appendix section B.2 explores this concern. We estimate the direct relationship between the reduction in sensitivity to paycheck receipt and debt paydown. Appendix Table A4 shows that this direct relationship is far from statistically significant in all specifications and the point estimate is positive in several specification - the opposite of what would be expected under the hypothesis that a reduction in sensitivity as resources increase leads to higher debt paydown.

\subsection{Robustness of Estimating Sensitivity}

Appendix B.3 shows that our results are robust to different ways of estimating the sensitivity to paycheck receipt. In the baseline, we require 45 days of positive spending to include a user in our sample. In Appendix Table A5 we replicate the analysis requiring 40 or 50 days instead. The relationship between consumption patterns and debt paydown is unaffected.

In the baseline specification, spending is also measured in logs and on a daily level. Instead, the first two columns of Table A6 use sensitivity estimates based on the actual amount spent and normalizes those estimates by average spending. The third and fourth columns use weekly spending instead of daily spending. The last two columns use sensitivity estimates based only on debit card spending, excluding any spending on credit cards. All results are very similar to the baseline estimates in Table 12.

\subsection{Robustness of Measuring Sophistication}

Low Levels of Sensitivity From a theoretical perspective, the distinction between sophisticated and naive agents becomes meaningless when users have very low or no short-run impatience. Relatedly, users with low levels of sensitivity to paycheck receipt are difficult to classify as either sophisticated or naive. With a low initial level of sensitivity, any potential reduction in the observed sensitivity which could identify a user as sophisticated is relatively low. Therefore such a reduction is less likely to be picked up in the estimation.

In Table 13, we exclude users with low levels of sensitivity. Starting with the baseline sample, we subsequently exclude users with the $10 \%, 15 \%$, and $20 \%$ lowest estimated levels of sensitivity to paycheck receipt. Despite the reduction in sample size, the estimated differences between sophisticated and naive agents remain statistically significant and of similar magnitude. ${ }^{27}$ Consistent with theory, the differences between sophisticated and naive agents are indeed driven by those agents with higher levels of short-run impatience rather than those with relatively low or no short-run impatience.

Different Classifications of Users Appendix B.4 provides additional robustness checks on the classification of users as either sophisticated or naive. Ideally, users should be classified the same irrespective of whether estimates are based on short-run consumables or restaurant and entertainment

completely smooths consumption.

${ }^{27}$ Note that the average level of sensitivity and its standard deviation in the sample also changes as we drop observations. So differences in the coefficients - or lack thereof - cannot be interpreted as implying a different sized effect (or lack thereof). The estimated coefficients across the different sample are not statistically different from each other. 
spending only. Appendix Table A7 shows that results are very similar to the baseline when only consistently-classified users are included. If anything, the point estimates are more similar across categories, supporting the notion that previously misclassified users lead to additional noise in the estimation.

Classification into sophisticated and naive is based on the effect of higher resources on sensitivity to paycheck receipt. When estimating this effect, resources are instrumented for by hypothetical balances as outlined in Section 4.2. This addresses the concern that past consumption levels may affect both the level of resources, as well as spending through unobservables such as a taste for consumption. This could lead to a negative coefficient absent any sophistication by the user. To understand the importance of this concern, we replicate the results classifying users as sophisticated or naive based on OLS instead of IV estimates of the effect of resources. If the endogeneity concern is important, a substantial number of users will be misclassified when using OLS estimates and the estimated differences between the two groups should be smaller. Indeed, Appendix Table A7 finds smaller differences between sophisticated and naive individuals which are mostly statistically insignificant, reinforcing the need to instrument for the level of resources.

\subsection{Alternative Explanations for Sensitivity to Paycheck}

Consumption spending may be sensitive to paycheck receipt for reasons other than short-run impatience. This section argues that such alternative explanations cannot explain the joint patterns of consumption spending and debt paydown.

Credit Constraints One possible cause of consumption spending sensitivity to paycheck receipt is credit constraints. If users are credit constrained and suffer an expense shock, they have to wait until the next paycheck to incur the expense, making spending sensitive to paycheck receipt. Therefore, throughout this paper, the estimation of the sensitivity to paycheck receipt is based only on times when credit constraints are unlikely to have played a role. In this section, we replicate the main results using different ways of excluding periods of potential credit constraint. The baseline specification requires spending in the given category to be affordable in the pre-paycheck week. The first alternative takes into account that users may want to hold a buffer stock of resources at all times. It requires that spending in the given category would have been affordable in the pre-paycheck week without reducing a consumer's resources below a buffer stock, measured as the $5^{\text {th }}$ percentile of observed resources. The second alternative requires that the payweek's total discretionary spending, rather than just category-specific spending would have been affordable in the previous week. There is substantial heterogeneity across users. The majority have considerable borrowing capacity left on their cards, an average of about $\$ 11,000$, as shown in Table 1. This group is never classified as likely constrained. Some users, however, regularly could not have afforded payweek spending in the previous week. Across all users, the baseline specification excludes about $20 \%$ of all days with positive spending as possibly credit constrained. Requiring total discretionary spending to be affordable or taking a buffer stock into account increases the number of excluded days to $22 \%$ and $28 \%$, respectively. Appendix Table A1 shows that the estimated sensitivity decreases slightly when filtering out pay cycles in which the user may have been credit constrained. However, the estimated sensitivity would decrease even if credit constraints did not play any role, since the excluded pay cycles are those with the highest 
spending. On the individual level, the estimated sensitivities are highly correlated across the different measures. $^{28}$ Table 14 replicates the main results using sensitivity estimates based on the different restrictions. Throughout, the results are very similar to the baseline specification.

Habits, Non-Separabilities in Consumption, or Social Coordination Habits coinciding with payweeks are another possible explanation for higher spending during payweeks. For instance, some people may have a habit of going out for "date night" every two weeks. For some of them, this might by chance overlap with the receipt of their paycheck. Alternatively, some people may rationally coordinate some purchases with when they get paid. Or they may coordinate consumption spending with their potentially credit-constrained or present-biased friends or colleagues. However, if the estimated sensitivity of consumption were caused by habits, non-separabilities between consumption, or social coordination, there is no reason to expect these users to have differential sensitivity depending on their resources or ability to adhere to their debt repayment plans in the way observed in the data. Therefore, the estimated sensitivity to paycheck receipt is at least partially driven by short-run impatience. Otherwise, it would not relate to debt paydown in exactly the way predicted by present bias.

Time-Consistent Preferences with a High Discount Factor For consumers who live paycheck to paycheck, time-consistent preferences with a very high discount factor can lead consumption spending to be higher early in the pay cycle. Similarly, consumers with a higher discount rate would also reduce their debt balances less. This is unlikely to be driving the results. First, the discount factor that would be necessary to lead to sensitivity of consumption spending over a two week horizon is so high that it is generally considered to be implausible, given consumers' relative patience in the longrun. ${ }^{29}$ Second, time-consistent consumers should have no issue sticking to their original plans. In our setting, a time-consistent consumer with a high discount factor is likely to be classified as naive. For both time-consistent as well as naive present-biased consumers, the discount factor between any two periods does not vary with resource levels and their sensitivity to paycheck receipt should be unaffected. However, we find that these consumers follow their plans substantially less than consumers classified as sophisticated. Time-consistent preferences with a high discount factor cannot explain why consumers whose consumption spending becomes less sensitive when resources are higher are more able to stick to their debt paydown plans.

\subsection{Alternative Explanations for Failing to Stick to Plan}

Loss of Income A substantial loss of income, for instance from job loss, could render households unable to follow their original plan to reduce debt levels. However, all users in our sample have regular paychecks throughout the sample period. Therefore they do not experience a substantial reduction in their income which could force them to abandon their original plan.

\footnotetext{
${ }^{28}$ Appendix Table A1 also shows that, within each consumption category, the correlation between sensitivity estimates with different restrictions is more than $90 \%$. Across the two spending categories - short-run consumables or restaurant and entertainment spending only - the estimates are also similar with correlations between $55 \%$ and $65 \%$.

${ }^{29}$ Shapiro (2005) outlines this argument for the monthly horizon considered in his paper.
} 
Aspirational Plans and Alternative Interpretations of Plan Meaning When prompted by ReadyForZero to state how much they want to reduce their debt each month, users may differ in what they understand a plan to be. For instance, some users may view their planned paydown as an aspirational goal rather than as a realistic plan which they are likely to stick to. However, differences in interpreting what a plan means should not affect how consumers allocate consumption over the pay cycle and therefore cannot explain the systematic relationship between consumption patterns and the extent to which consumers follow their plan. Additionally, the debt reduction plan at ReadyForZero is not binding and there are no consequences for not following through with a plan. Rather, it was used to help users calculate their monthly payment for each credit card. There are therefore no obvious incentives for users to lie about their planned paydown, other than for their own aspirations or similar motives as mentioned above. This cheap talk nature of the plan on ReadyForZero also means it is not a commitment device and we therefore do not expect individuals to be sophisticated simply by signing up for the service.

Better Monitoring of Financial Situation Some users may be paying more attention to their financial situation than others. This could lead them to allocate more of their spending to times when their resources are high, such as right after receiving a paycheck, and to generally have a higher marginal propensity to consume when resources are high. At the same time, paying more attention would also make them more successful in following through with planned paydown. However, this would predict that users pay down more when they are more responsive to paycheck receipt and when their marginal propensity to consume increases with resources. This is the opposite of our results: We classify users as sophisticated when they have a lower - not higher - marginal propensity to consume when overall resources are high and find that these users are better at following plans. At the same time, higher propensity to consume after paycheck receipt is associated with lower debt reduction. Better monitoring and alignment of spending with times of high resources would predict the opposite of what we find and, therefore, cannot explain our results.

Lack of Planning Skills or Overoptimism A lack of planning skills or overoptimism could lead some users to make overly ambitious debt paydown plans and, hence, explain their failure to stick to their plans. Such bad planning either due to overoptimism or lack of planning skills in general could also lead to sensitivity of consumption spending to paycheck receipt. Users may be overoptimistic about the probability of receiving additional resources in the second week of a pay cycle or underestimate the cost of their first week's planned consumption. As a result, they might spend more of the paycheck when they receive it, and when additional resources fail to materialize, they reduce expenditures. However, there is no reason why the extent of overoptimism or lack of planning skills should vary systematically with the week to week changes in an individual's level of resources. There is also no reason why variations in resources affecting sensitivity of consumption spending should closely relate to debt paydown. Furthermore, it is not the case that sophisticated and naive users differ in the aggressiveness of their plans. Hence, overoptimism alone does not predict the systematic differences between sophisticated and naive agents observed in the data. 
Lack of Financial Literacy Several papers have shown that consumers' lack of basic financial literacy leads many to make suboptimal financial decisions. ${ }^{30}$ A lack of financial literacy alone, however, cannot explain the results in this paper. Lack of financial literacy does not necessarily lead to sensitivity of consumption to paycheck receipt. However, consumers who better understand the implications of their financial decisions may also be better at planning and allocating resources over their twoweek pay cycles, leading them to smooth consumption more. That being said, a lack of financial literacy would not predict that differences in the effect of resources on the sensitivity to paycheck receipt systematically predict which consumers are better able to follow their plan and reduce their debt levels. Furthermore, one may argue that financially literate individuals should have a higher marginal propensity to consume when resources are high (see the argument above about better monitoring) rather than the other way around, which is what we observe for sophisticates. Nevertheless, the results are consistent with some - or even most - consumers lacking a thorough understanding of financial matters in addition to some having present-biased preferences.

\section{Conclusion}

This paper shows that differences in consumers' short-run impatience and their sophistication about their own time-inconsistent preferences can help explain why some consumers plan to pay off expensive credit card balances but fail to do so. A set of theoretical papers has shown that common features in credit card contracts, such as teaser rates, disproportionally hurt consumers with behavioral biases (see Heidhues and Kőszegi, 2010). ${ }^{31}$ Whether credit markets should be regulated or not, however, crucially depends on whether individuals are aware of their behavioral biases or not. Regulations such as those in the CARD Act of 2009 might be justified by evidence that awareness of behavioral biases play a role in explaining credit card debt paydown. This regulation, for instance, prohibits issuers of sub-prime credit cards to backload fees, which would be very effective in preventing present-biased consumers from borrowing without fully internalizing the cost. ${ }^{32}$ The results also have important implications for how to help consumers get out of debt. For instance, mechanisms that make commitment to long-term plans attractive to consumers could be a promising and cost effective way to do so. One possibility would be to allow consumers to select a certain amount to be deducted from their regular paycheck to be put towards debt repayment, and to make it costly or complicated to change

\footnotetext{
${ }^{30}$ Lusardi and Tufano (2009) show that households with lower financial literacy report excessive debt balances more often. Bertrand and Morse (2011) find a lack of financial literacy among payday loan borrowers. Bernheim and Garrett (2003) and Bernheim, Garrett and Maki (2001) show that financial education increases savings. Hastings and Mitchell (2011) show that while short-run impatience is a strong predictor for retirement savings in Chile, financial literacy is also correlated with savings levels. Stango and Zinman (2009) show that households who exhibit exponential growth bias borrow more. Agarwal and Mazumder (2013) find that households with higher cognitive ability measured by math scores make fewer financial mistakes, such as suboptimal use of credit cards. Hastings, Madrian and Skimmyhorn (2013) provide an overview of this literature.

${ }^{31}$ Ponce-Rodriguez (2008) shows that banks in Mexico structure credit card contracts to exploit customers' potential behavioral biases. DellaVigna and Malmendier (2004) study how firms structure contracts with consumers who have self control issues. Several papers have explored the implications of behavioral biases for regulation and policy. Camerer et al. (2003) argue for the benefits of some paternalistic regulation in the face of behavioral biases, including potential present bias. Mullainathan, Schwartzstein and Congdon (2012) present a framework for the implications of potential behavioral biases for regulation and public finance. Gruber and Kőszegi (2004) study the implications of time-inconsistent preferences for the incidence of cigarette taxes.

${ }^{32}$ Agarwal et al. (2015) show that reductions in fees after the Credit CARD Act were not passed on to consumers. Agarwal et al. (forthcoming) also show why reductions in the cost of funds may not be passed on to credit card borrowers.
} 
this selection. In the literature, similar ideas have been explored in helping present-biased consumers save, for instance by Thaler and Benartzi (2004) or Ashraf, Karlan and Yin (2006).

The need for regulation crucially depends on whether individuals are aware (sophisticated) or unaware (naive) of their own short-run impatient preferences. This paper proposes a new empirical methodology to detecting short-run impatience and sophistication versus naivete in high-frequency transaction-level data of all spending, income, balances, and credit limits. Moreover, we are able to validate our empirical approach by comparing individuals' actual debt paydown to their debt paydown plans. This allows for the application of our methodology in future research using only spending and income data. To the best of our knowledge, no previous work exists distinguishing sophistication from naivete in observational data, even though the distinction of sophistication versus naivete is of utmost important for policy recommendations and in theoretical models. 


\section{References}

Ackerman, R.A., G. Fries, and R.A. Windle. 2012. "Changes in US Family Finances from 2007 to 2010: Evidence from the Survey of Consumer Finances." Federal Reserve Bulletin.

Agarwal, Sumit, and Bhashkar Mazumder. 2013. "Cognitive Abilities and Household Financial Decision Making." American Economic Journal: Applied Economics, 5(1): 193-207.

Agarwal, Sumit, Gene Amromin, Itzhak Ben-David, Souphala Chomsisengphet, and Douglas D. Evanoff. 2010. "Learning to Cope: Voluntary Financial Education and Loan Performance during a Housing Crisis." American Economic Review, 100(2): 495-500.

Agarwal, Sumit, John C. Driscoll, Xavier Gabaix, and David Laibson. 2008. "Learning in the Credit Card Market." National Bureau of Economic Research Working Paper 13822.

Agarwal, Sumit, Souphala Chomsisengphet, Neale Mahoney, and Johannes Stroebel. 2015. "Regulating Consumer Financial Products: Evidence from Credit Cards." The Quarterly Journal of Economics, 130(1): 111-164.

Agarwal, Sumit, Souphala Chomsisengphet, Neale Mahoney, and Johannes Stroebel. forthcoming. "Do Banks Pass Through Credit Expansions to Consumers Who Want to Borrow?" The Quarterly Journal of Economics.

Aguiar, Mark, and Erik Hurst. 2005. “Consumption versus Expenditure." Journal of Political Economy, 113(5): 919-948.

Akerlof, George A. 1991. "Procrastination and obedience." The American Economic Review, 81(2): 1-19.

Angeletos, George-Marios, David Laibson, Andrea Repetto, Jeremy Tobacman, and Stephen Weinberg. 2001. "The Hyperbolic Consumption Model: Calibration, Simulation, and Empirical Evaluation." The Journal of Economic Perspectives, 15(3): 47-68.

Ariely, D., and K. Wertenbroch. 2002. "Procrastination, deadlines, and performance: Self-control by precommitment." Psychological Science, 13(3): 219-224.

Ashraf, N., D. Karlan, and W. Yin. 2006. "Tying Odysseus to the mast: Evidence from a commitment savings product in the Philippines." Quarterly Journal of Economics, 121(2): 635-672.

Ausubel, Lawrence M. 1991. "The Failure of Competition in the Credit Card Market." American Economic Review, 81(1): 50-81.

Baker, Scott R. forthcoming. "Debt and the consumption response to household income shocks." Journal of Political Economy.

Baugh, Brian, Itzhak Ben-David, and Hoonsuk Park. 2014. "Disentangling financial constraints, precautionary savings, and myopia: household behavior surrounding federal tax returns." National Bureau of Economic Research.

Baugh, Brian, Jesse B Leary, Financial Conduct Authority, and Jialan Wang. 2017. "When Is It Hard to Make Ends Meet?"

Bernheim, B.D., and D.M. Garrett. 2003. "The effects of financial education in the workplace: Evidence from a survey of households." Journal of Public Economics, 87(7): 1487-1519.

Bernheim, B.D., D.M. Garrett, and D.M. Maki. 2001. "Education and saving: The long-term effects of high school financial curriculum mandates." Journal of Public Economics, 80(3): 435-465. 
Bertrand, M., and A. Morse. 2011. "Information Disclosure, Cognitive Biases, and Payday Borrowing." Journal of Finance, 66(6): 1865-1893.

Bricker, Jesse, Lisa J. Dettlinger, Alice Henriques, Joanne W. Hsu, Kevin B. Moore, John Sabelhaus, Jeffrey Thompson, and Richard A. Windle. 2014. "Changes in U.S. Family Finances from 2010 to 2013: Evidence from the Survey of Consumer Finances." Federal Reserve Bulletin.

Browning, Martin, and M. Dolores Collado. 2001. "The Response of Expenditures to Anticipated Income Changes: Panel Data Estimates." American Economic Review, 91(3): 681-692.

Camerer, Colin, Samuel Issacharoff, George Loewenstein, Ted O'Donoghue, and Matthew Rabin. 2003. "Regulation for Conservatives: Behavioral Economics and the Case for "Asymmetric Paternalism"." University of Pennsylvania Law Review, 151(3): 1211-1254.

Campbell, J., and A. Deaton. 1989. "Why is Consumption So Smooth?" Review of Economic Studies, 56(3): 357-373.

Carroll, C. 2001. "Theoretical Foundations of Buffer Stock Saving." Working Paper Johns Hopkins University.

Carroll, C. 2011. "Theoretical Foundations of Buffer Stock Saving." Working Paper Johns Hopkins University.

Carroll, G.D., J.J. Choi, D. Laibson, B.C. Madrian, and A. Metrick. 2009. “Optimal Defaults and Active Decisions." Quarterly Journal of Economics, 124(4): 1639-1674.

Choi, J.J., D. Laibson, B.C. Madrian, and A. Metrick. 2004. "Default Effects and 401 (k) Savings Behavior." Perspectives on the economics of aging.

DellaVigna, S. 2009. "Psychology and Economics: Evidence from the Field." Journal of Economic Literature, 47(2): 315-372.

DellaVigna, S., and U. Malmendier. 2004. "Contract Design and Self-Control: Theory and Evidence." Quarterly Journal of Economics, 119(2): 353-402.

DellaVigna, S., and U. Malmendier. 2006. "Paying not to go to the gym." American Economic Review, 96(3): 694-719.

Fang, H., and D. Silverman. 2009. "Time-inconsistency and Welfare Program Participation: Evidence from the NLSY." International Economic Review, 50(4): 1043-1077.

Fang, Hanming, and Yang Wang. 2015. "Estimating dynamic discrete choice models with hyperbolic discounting, with an application to mammography decisions." International Economic Review, 56(2): 565-596.

Gelman, Michael, Shachar Kariv, Matthew D Shapiro, Dan Silverman, and Steven Tadelis. 2014. "Harnessing naturally occurring data to measure the response of spending to income." Science, 345(6193): 212-215.

Gourinchas, P.-O., and J. A. Parker. 2002. “Consumption over the Life Cycle.” Econometrica, 70(1): 4789.

Gruber, J., and B. Köszegi. 2004. "Tax incidence when individuals are time-inconsistent: the case of cigarette excise taxes." Journal of Public Economics, 88(9): 1959-1987.

Harris, C., and D. Laibson. 2002. "Hyperbolic Discounting and Consumption." Advances in Economics and Econometrics: Theory and Applications, 1: 258-298. 
Hastings, J., and E. Washington. 2010. "The First of the Month Effect: Consumer Behavior and Store Responses." American Economic Journal: Economic Policy, 2(2): 142-162.

Hastings, Justine S., and Olivia S. Mitchell. 2011. "How Financial Literacy and Impatience Shape Retirement Wealth and Investment Behaviors." National Bureau of Economic Research Working Paper 16740.

Hastings, Justine S., Brigitte C. Madrian, and William L. Skimmyhorn. 2013. "Financial Literacy, Financial Education, and Economic Outcomes." Annual Review of Economics, 5(1): 347-373.

Heidhues, P., and B. Kőszegi. 2010. “Exploiting Naïvete about Self-control in the Credit Market." American Economic Review, 100(5): 2279-2303.

Hsieh, C.T. 2003. "Do Consumers React to Anticipated Income Changes? Evidence from the Alaska Permanent Fund." American Economic Review, 93(1): 397-405.

Jappelli, T., and L. Pistaferri. 2010. "The Consumption Response to Income Changes." Annual Review of Economics, 2: 479-506.

Kaur, Supreet, Michael Kremer, and Sendhil Mullainathan. 2010. "Self-Control and the Development of Work Arrangements." American Economic Review, 100(2): 624-28.

Keys, Benjamin J, and Jialan Wang. 2016. “Minimum Payments and Debt Paydown in Consumer Credit Cards." Working Paper.

Laibson, D. 1997. "Golden Eggs and Hyperbolic Discounting." Quarterly Journal of Economics, 112(2): 443-478.

Laibson, D., A. Repetto, and J. Tobacman. 2007. "Estimating Discount Functions with Consumption Choices over the Lifecycle." Working Paper.

Laibson, David, Andrea Repetto, and Jeremy Tobacman. 2003. "A Debt Puzzle." Knowledge, Information, and Expectations in Modern Macroeconomics: In Honor of Edmund Strother Phelps, 228.

Lusardi, Annamaria, and Peter Tufano. 2009. "Debt Literacy, Financial Experiences, and Overindebtedness." National Bureau of Economic Research Working Paper 14808.

Madrian, BC, and DF Shea. 2001. "The Power of Suggestion: Inertia in 401 (k) Participation and Savings Behavior." Quarterly Journal of Economics, 116(4): 1149-1187.

Meier, S., and C. Sprenger. 2010. "Present-Biased Preferences and Credit Card Borrowing." American Economic Journal: Applied Economics, 2(1): 193-210.

Mullainathan, Sendhil, Joshua Schwartzstein, and William J. Congdon. 2012. "A Reduced-Form Approach to Behavioral Public Finance." Annual Review of Economics, 4(1): 511-540.

O'Donoghue, Ted, and Matthew Rabin. 1999. “Doing It Now or Later." American Economic Review, 89(1): 103-124.

Olafsson, A., and M. Pagel. 2016. "The Liquid Hand-to-Mouth: Evidence from Personal Finance Management Software." Working Paper.

Parker, Jonathan A. 1999. "The Reaction of Household Consumption to Predictable Changes in Social Security Taxes." American Economic Review, 89(4): 959-973.

Paserman, M.D. 2008. "Job Search and Hyperbolic Discounting: Structural Estimation and Policy Evaluation." The Economic Journal, 118(531): 1418-1452. 
Ponce-Rodriguez, Alejandro. 2008. "Rate Offers in the Credit Card Market: Evidence from Mexico." Dissertation Stanford University.

Scholnick, B. 2013. "Consumption Smoothing after the Final Mortgage Payment: Testing the Magnitude Hypothesis." Review of Economics and Statistics, 95(4): 1444-1449.

Shapiro, J.M. 2005. "Is there a daily discount rate? Evidence from the food stamp nutrition cycle." Journal of Public Economics, 89(2-3): 303-325.

Shui, H., and L.M. Ausubel. 2005. “Time Inconsistency in the Credit Card Market." Working Paper.

Skiba, Paige Marta, and Jeremy Tobacman. 2008. "Payday Loans, Uncertainty and Discounting: Explaining Patterns of Borrowing, Repayment, and Default." Working Paper.

Souleles, N.S. 1999. "The Response of Household Consumption to Income Tax Refunds." American Economic Review, 89(4): 947-958.

Stango, Victor, and Jonathan Zinman. 2009. "Exponential Growth Bias and Household Finance." The Journal of Finance, 64(6): 2807-2849.

Stephens, Jr, M. 2006. "Paycheque Receipt and the Timing of Consumption." The Economic Journal, 116(513): 680-701.

Strotz, Robert Henry. 1955. "Myopia and inconsistency in dynamic utility maximization." The Review of Economic Studies, 23(3): 165-180.

Thaler, R.H., and S. Benartzi. 2004. "Save More Tomorrowï $£_{i}:$ Using Behavioral Economics to Increase Employee Saving." Journal of Political Economy, 112(1): 164-187.

Tobacman, J. 2007. “The Partial Naivete Euler Equation.” Mimeo.

Zhang, C Yiwei. 2017. “Consumption Responses to Pay Frequency: Evidence from 'Extra' Paychecks." In Working Paper. 
Figure 1: Simulated Life-cycle Profiles and CEX Consumption and Income Data
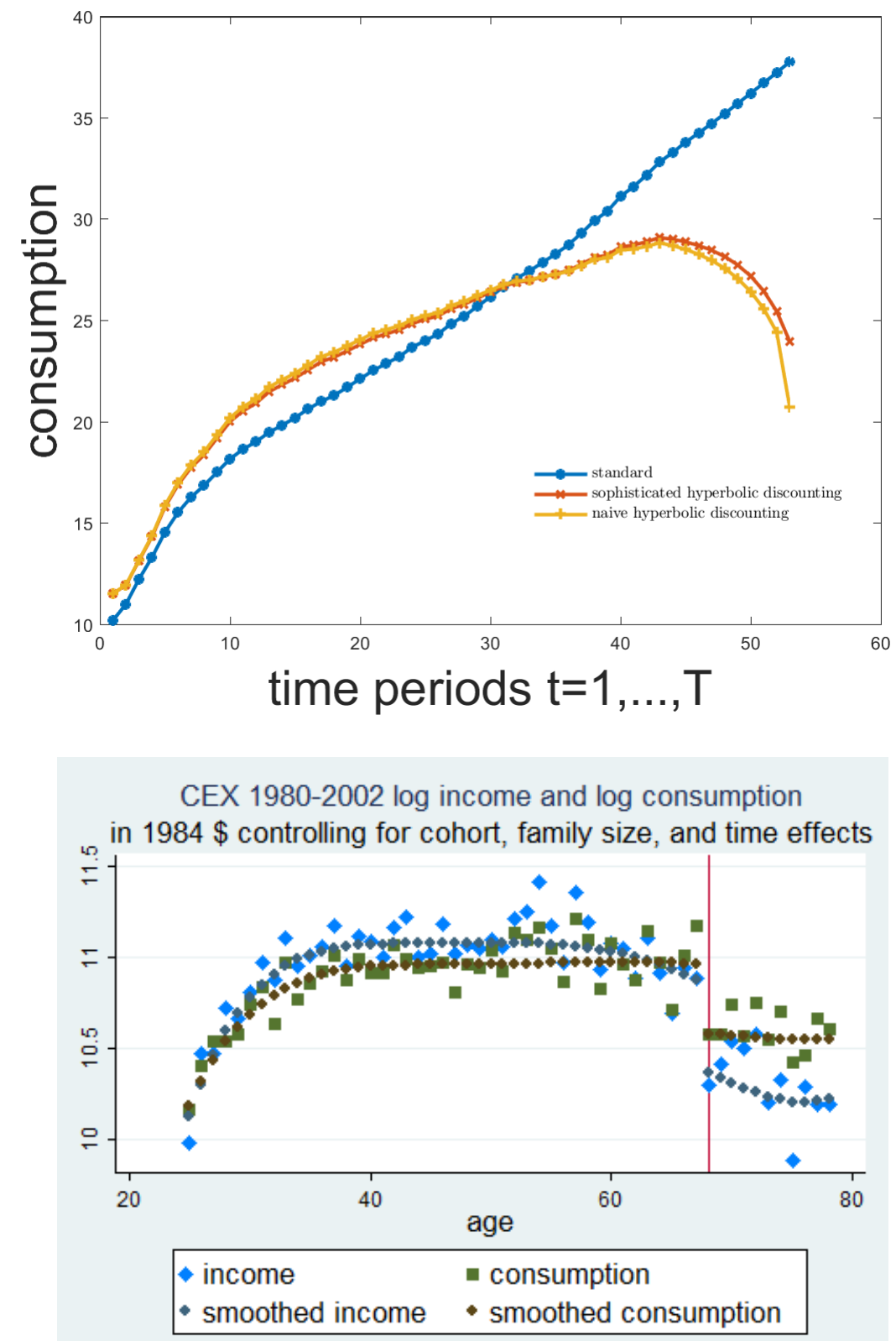

This figure contrasts the average consumption profiles using the simulated data of 516 agents that have either sophisticated, naive, or standard preferences with the average CEX consumption and income data. The calibration is displayed in Table 5 and we set $\beta=0.7$. The unit of consumption and income is the log of 1984 dollars controlling for cohort, family size, and time effects. 
Figure 2: Mean Paydown after 90 Days by Sensitivity Quintiles

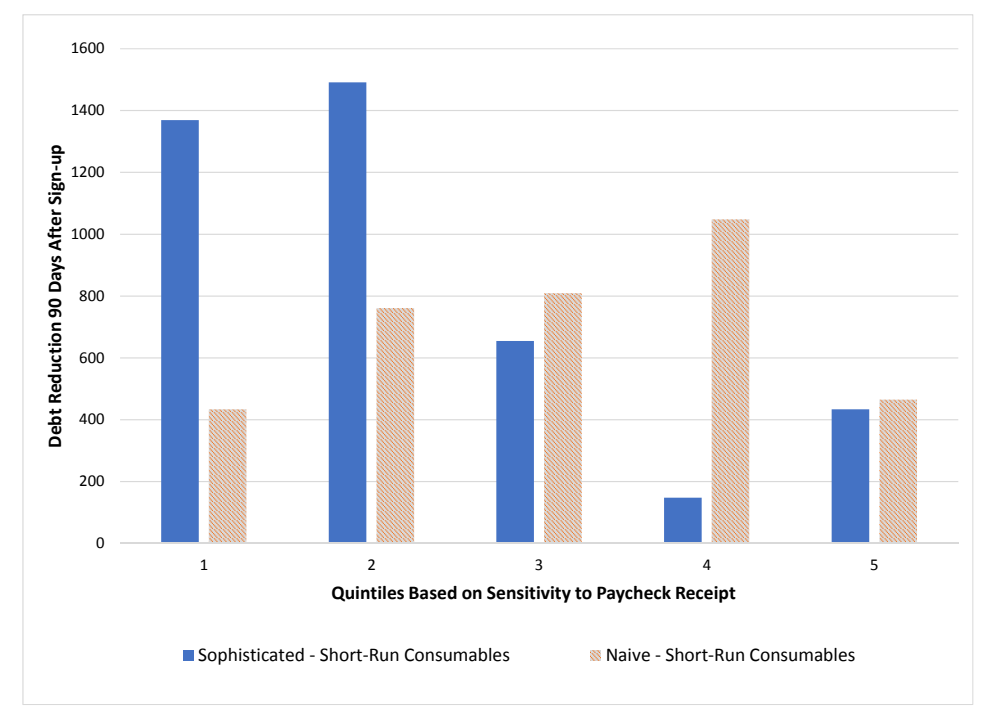

The figure shows the mean paydown over the first 90 days after sign-up for consumers classified as sophisticated and naive. For each type, consumers are sorted into five groups based on their estimated sensitivity to paycheck receipt. 
Table 1: Summary Statistics - Income and Assets

\begin{tabular}{|c|c|c|c|c|c|c|}
\hline & \multicolumn{6}{|c|}{ Income and Assets } \\
\hline & Obs. & Mean & Std. Dev. & $\begin{array}{l}\text { 25th } \\
\text { pctile }\end{array}$ & $\begin{array}{l}\text { 50th } \\
\text { pctile }\end{array}$ & $\begin{array}{l}\text { 75th } \\
\text { pctile }\end{array}$ \\
\hline \multicolumn{7}{|l|}{ Users } \\
\hline Days in sample & 516 & 415 & 150 & 262 & 430 & 584 \\
\hline Days in sample after sign-up & & 392 & 231 & 274 & 401 & 588 \\
\hline $\mathrm{Nr}$ of paychecks & & 28 & 12 & 19 & 26 & 38 \\
\hline $\mathrm{Nr}$ of paychecks - regular paycycles & & 21 & 14 & 12 & 20 & 31 \\
\hline \multicolumn{7}{|l|}{ Income } \\
\hline Avg. monthly income- regular paycycles & 516 & 3,778 & 1,830 & 2,469 & 3,460 & 4,671 \\
\hline Median monthly income- regular paycycles & & 3,744 & 1,810 & 2,450 & 3,440 & 4,564 \\
\hline Avg. monthly non-paycheck income & & 295 & 417 & 0 & 135 & 406 \\
\hline Median monthly non-paycheck income & & 69 & 252 & 0 & 0 & 0 \\
\hline Fraction of regular income & & 0.89 & 0.11 & 0.83 & 0.92 & 0.99 \\
\hline \multicolumn{7}{|l|}{ Assets } \\
\hline Credit Card Debt - \$ & 516 & 13,808 & 13,319 & 4,582 & 9,777 & 18,331 \\
\hline Credit Card Debt - rel. to income & & 3.81 & 3.35 & 1.40 & 2.90 & 4.92 \\
\hline Cash Balances - \$ & & 4,822 & 7,550 & 911 & 2,099 & 5,178 \\
\hline Cash Balances - rel. to income & & 1.28 & 1.86 & 0.31 & 0.64 & 1.54 \\
\hline Total Credit - $\$$ & & 24,684 & 22,418 & 8,573 & 18,000 & 33,475 \\
\hline Total Credit - rel. to income & & 6.80 & 5.66 & 2.70 & 5.16 & 8.97 \\
\hline Available Credit - $\$$ & & 10,722 & 14,177 & 1,550 & 4,973 & 14,725 \\
\hline Available Credit - rel. to income & & 3.04 & 4.13 & 0.48 & 1.47 & 3.89 \\
\hline APR paid on debt - mean & 401 & 16.71 & 5.65 & 13.24 & 16.33 & 20.35 \\
\hline APR paid on debt - median & & 16.77 & 6.57 & 13.24 & 16.24 & 20.45 \\
\hline
\end{tabular}

The table shows mean, median, and the $25^{\text {th }}$ and $75^{\text {th }}$ percentile for how long users are observed in the sample, their income, and assets. All variables are winsorized at the $1 \%$ level. 
Table 2: Summary Statistics - Spending

\begin{tabular}{|c|c|c|c|c|c|c|}
\hline & \multicolumn{6}{|c|}{ Monthly Spending } \\
\hline & Obs. & Mean & Std. Dev. & $\begin{array}{l}\text { 25th } \\
\text { pctile }\end{array}$ & $\begin{array}{l}\text { 50th } \\
\text { pctile }\end{array}$ & $\begin{array}{l}\text { 75th } \\
\text { pctile }\end{array}$ \\
\hline \multicolumn{7}{|l|}{ Discretionary Spending } \\
\hline \multicolumn{7}{|l|}{ Total } \\
\hline Avg. \$ & 516 & 1,795 & 939 & 1,127 & 1,593 & 2,271 \\
\hline Avg. relative to avg. income & & 0.52 & 0.24 & 0.35 & 0.47 & 0.63 \\
\hline Median $\$$ & & 1,817 & 1,044 & 1,117 & 1,638 & 2,311 \\
\hline Median relative to avg. incom $\epsilon$ & & 0.52 & 0.26 & 0.35 & 0.49 & 0.65 \\
\hline \multicolumn{7}{|l|}{ Non-Durable } \\
\hline Avg. $\$$ & 516 & 1,026 & 540 & 635 & 920 & 1,291 \\
\hline Avg. relative to avg. income & & 0.30 & 0.15 & 0.20 & 0.28 & 0.36 \\
\hline Median \$ & & 1,030 & 595 & 624 & 942 & 1,314 \\
\hline Median relative to avg. income & & 0.30 & 0.15 & 0.21 & 0.28 & 0.37 \\
\hline \multicolumn{7}{|l|}{ Short-run Consumables } \\
\hline Avg. $\$$ & 516 & 548 & 285 & 336 & 500 & 681 \\
\hline Avg. relative to avg. income & & 0.16 & 0.08 & 0.10 & 0.14 & 0.20 \\
\hline Median $\$$ & & 564 & 330 & 340 & 514 & 718 \\
\hline Median relative to avg. income & & 0.16 & 0.10 & 0.10 & 0.15 & 0.21 \\
\hline \multicolumn{7}{|l|}{ Restaurant\&Entertainment } \\
\hline Avg. $\$$ & 516 & 290 & 165 & 172 & 256 & 370 \\
\hline Avg. relative to avg. income & & 0.09 & 0.05 & 0.05 & 0.08 & 0.11 \\
\hline Median $\$$ & & 277 & 181 & 152 & 246 & 364 \\
\hline Median relative to avg. income & & 0.08 & 0.05 & 0.04 & 0.07 & 0.10 \\
\hline \multicolumn{7}{|l|}{ Reqular Payments } \\
\hline Avg. \$ & 516 & 1,205 & 784 & 619 & 1,050 & 1,673 \\
\hline Avg. relative to avg. income & & 0.33 & 0.19 & 0.20 & 0.31 & 0.44 \\
\hline Median $\$$ & & 1,264 & 965 & 475 & 1,096 & 1,902 \\
\hline Median relative to avg. income & & 0.35 & 0.24 & 0.15 & 0.33 & 0.50 \\
\hline
\end{tabular}

The table shows mean, median, and the $25^{\text {th }}$ and $75^{\text {th }}$ percentile for spending of the users in the sample used throughout the paper. All variables are winsorized at the $1 \%$ level. 
Table 3: Summary Statistics - Plans and Paydown

\begin{tabular}{|c|c|c|c|c|c|c|}
\hline & \multicolumn{6}{|c|}{ Plans and Debt Paydown } \\
\hline & Obs. & Mean & Std. Dev. & $\begin{array}{l}\text { 25th } \\
\text { pctile }\end{array}$ & $\begin{array}{l}\text { 50th } \\
\text { pctile }\end{array}$ & $\begin{array}{l}\text { 75th } \\
\text { pctile }\end{array}$ \\
\hline \multicolumn{7}{|l|}{ Plans } \\
\hline Planned Paydown - monthly - \$ & 516 & 891 & 1,112 & 353 & 598 & 1,017 \\
\hline Planned Paydown - monthly - \% of debt & & 0.12 & 0.18 & 0.04 & 0.06 & 0.11 \\
\hline Planned Paydown - monthly - \% of income & & 0.25 & 0.37 & 0.11 & 0.18 & 0.30 \\
\hline Planned Paydown - 90 days - $\$$ & 516 & 2,482 & 2,710 & 926 & 1,792 & 2,992 \\
\hline Planned Paydown - 90 days - $\%$ of debt & & 0.28 & 0.26 & 0.11 & 0.18 & 0.33 \\
\hline Planned Paydown - 180 days $-\$$ & 516 & 4,650 & 4,972 & 1,785 & 3,288 & 5,951 \\
\hline Planned Paydown - 180 days - $\%$ of debt & & 0.47 & 0.30 & 0.22 & 0.36 & 0.66 \\
\hline \multicolumn{7}{|l|}{ Debt Paydown } \\
\hline Change in Debt - 90 days $-\$$ & 516 & -734 & 3,041 & $-1,291$ & -222 & 292 \\
\hline Change in Debt - 90 days - \% & & 0.02 & 0.92 & -0.14 & -0.02 & 0.04 \\
\hline Change in Debt - 180 days $-\$$ & 516 & -977 & 3,858 & $-2,087$ & -418 & 479 \\
\hline Change in Debt - 180 days - $\%$ & & 0.26 & 4.04 & -0.20 & -0.04 & 0.06 \\
\hline Shortfall relative to plan - 90 days - $\$$ & 516 & 1,748 & 3,466 & 429 & 1,417 & 2,986 \\
\hline Shortfall relative to plan - 90 days - $\%$ & & 0.85 & 2.45 & 0.39 & 0.84 & 1.19 \\
\hline Shortfall relative to plan - 180 days $-\$$ & 516 & 3,673 & 5,224 & 970 & 2,813 & 5,410 \\
\hline Shortfall relative to plan - 180 days - $\%$ & & 1.16 & 4.28 & 0.50 & 0.88 & 1.15 \\
\hline Payments made -90 days & 516 & 3,160 & 4,398 & 660 & 1,660 & 3,957 \\
\hline Payments made -180 days & & 5,823 & 7,324 & 1,339 & 3,490 & 7,747 \\
\hline
\end{tabular}

The table shows mean, median, and $25^{\text {th }}$ and $75^{\text {th }}$ percentile for planned and actual debt paydown of the users in the sample used throughout the paper. All variables are winsorized at the $1 \%$ level. 


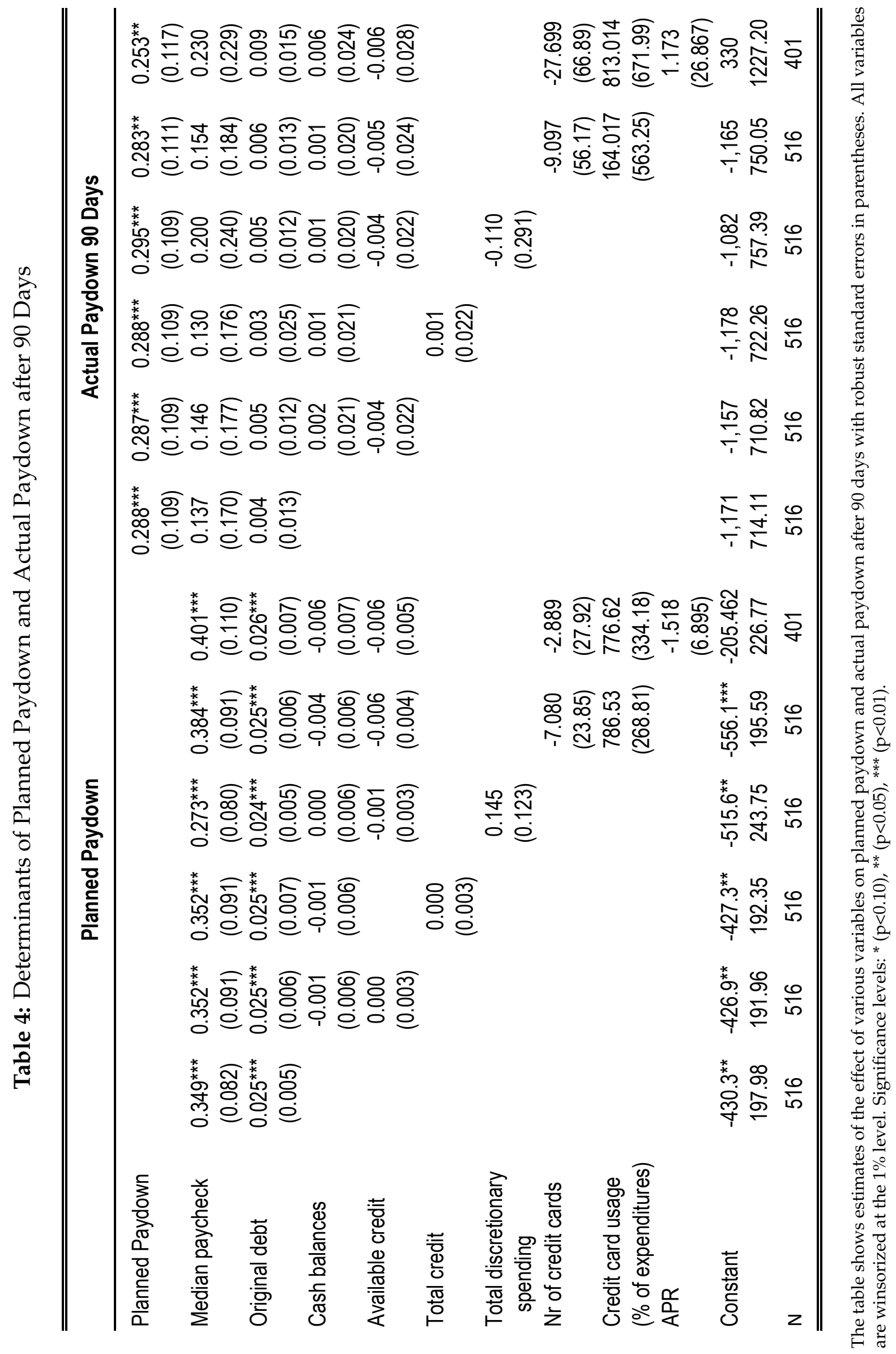


Table 5: Calibration

\begin{tabular}{cccccccccccc}
\hline \hline \multicolumn{11}{c}{ Preference and Environmental Parameters } \\
$\mu_{\mathrm{T}}$ & $\sigma_{\mathrm{T}}$ & $\mathrm{p}$ & $\mathrm{G}_{\mathrm{t}}$ & $\mathrm{R}^{\mathrm{s}}$ & $\mathrm{R}^{\mathrm{b}}$ & $\mathrm{A}_{0} / \mathrm{P}_{0}$ & $\mathrm{Ret}$ & $\mathrm{T}-$ Ret & $\delta$ & $\theta$ & $\beta$ \\
\hline 0 & 0.8 & $0.1 \%$ & $e^{Y_{t+1}-Y_{t}}$ & 1.031 & 1.167 & 1 & 11 & 54 & 0.94 & 2 & 0.7 \\
\hline \hline
\end{tabular}

The table shows all calibrated parameters for the life-cycle model. The simulation results in Tables 6 to 8 show a range of hyperbolic discount factors, $\beta$. Furthermore, we assume for the sophisticated agent $\hat{\beta}=\beta<1$, for the naive agent $\hat{\beta}=1$ and $\beta<1$, and for the standard agent $\hat{\beta}=\beta=1$. For the illustration in Figure 1 , we set $\beta=0.7$. 
Table 6: Simulated MPC Regression Results

\begin{tabular}{|c|c|c|c|c|}
\hline & \multicolumn{4}{|c|}{ MPC Regression Coefficient $b_{1}$} \\
\hline & Obs. & standard & sophisticated & naïve \\
\hline \multicolumn{5}{|c|}{ Short-run Impatience $\boldsymbol{\beta}$} \\
\hline 0.6 & $516 \times 26$ & $\begin{array}{c}0.324^{\star \star *} \\
(0.037)\end{array}$ & $\begin{array}{c}0.803^{\star \star *} \\
(0.023)\end{array}$ & $\begin{array}{c}0.876^{\star \star \star} \\
(0.023)\end{array}$ \\
\hline 0.65 & $516 \times 26$ & $\begin{array}{c}0.324^{* * *} \\
(0.037)\end{array}$ & $\begin{array}{c}0.743^{* * *} \\
(0.028)\end{array}$ & $\begin{array}{c}0.811^{* * *} \\
(0.028)\end{array}$ \\
\hline 0.7 & $516 \times 26$ & $\begin{array}{c}0.324^{\star * *} \\
(0.037)\end{array}$ & $\begin{array}{c}0.703^{* * *} \\
(0.033)\end{array}$ & $\begin{array}{c}0.737^{* * *} \\
(0.035)\end{array}$ \\
\hline 0.75 & $516 \times 26$ & $\begin{array}{c}0.324^{\star \star *} \\
(0.037)\end{array}$ & $\begin{array}{c}0.642^{\star \star *} \\
(0.038)\end{array}$ & $\begin{array}{c}0.666^{* * *} \\
(0.040)\end{array}$ \\
\hline 0.8 & $516 \times 26$ & $\begin{array}{c}0.324^{* * *} \\
(0.037)\end{array}$ & $\begin{array}{c}0.582^{\star * *} \\
(0.041)\end{array}$ & $\begin{array}{c}0.597^{\star \star *} \\
(0.043)\end{array}$ \\
\hline 0.85 & $516 \times 26$ & $\begin{array}{c}0.324^{* * *} \\
(0.037)\end{array}$ & $\begin{array}{c}0.519^{\star \star *} \\
(0.042)\end{array}$ & $\begin{array}{c}0.530^{* * *} \\
(0.044)\end{array}$ \\
\hline 0.9 & $516 \times 26$ & $\begin{array}{c}0.324^{\star * *} \\
(0.037)\end{array}$ & $\begin{array}{c}0.459^{* * *} \\
(0.042)\end{array}$ & $\begin{array}{c}0.465^{* * *} \\
(0.043)\end{array}$ \\
\hline
\end{tabular}

The table shows the average regression coefficient results of equation (1) using the simulated data of 516 agents with 26 bimonthly data points each after a burn-in period of 60 months with standard errors displayed in parentheses. The regression results are similar for different assumptions about the number of data points, initial savings levels, and time horizons. 
Table 7: Simulated Sophistication Regression Results - MPC

\begin{tabular}{|c|c|c|c|c|}
\hline & \multicolumn{4}{|c|}{ Sophistication Regression Coefficient $b_{3}$} \\
\hline & Obs. & standard & sophisticated & naïve \\
\hline \multicolumn{5}{|c|}{ Short-run Impatience $\beta$} \\
\hline 0.6 & $516 \times 26$ & $\begin{array}{l}-0.344 \\
(0.474)\end{array}$ & $\begin{array}{l}-0.178^{*} \\
(0.143)\end{array}$ & $\begin{array}{l}-0.015 \\
(0.345)\end{array}$ \\
\hline 0.65 & $516 \times 26$ & $\begin{array}{l}-0.344 \\
(0.474)\end{array}$ & $\begin{array}{c}-0.470^{* \star *} \\
(0.171)\end{array}$ & $\begin{array}{c}0.106 \\
(0.433)\end{array}$ \\
\hline 0.7 & $516 \times 26$ & $\begin{array}{l}-0.344 \\
(0.474)\end{array}$ & $\begin{array}{c}-0.223^{* * *} \\
(0.476)\end{array}$ & $\begin{array}{c}0.183 \\
(0.538)\end{array}$ \\
\hline 0.75 & $516 \times 26$ & $\begin{array}{l}-0.344 \\
(0.474)\end{array}$ & $\begin{array}{c}-0.890^{* * *} \\
(0.388)\end{array}$ & $\begin{array}{c}0.205 \\
(0.621)\end{array}$ \\
\hline 0.8 & $516 \times 26$ & $\begin{array}{l}-0.344 \\
(0.474)\end{array}$ & $\begin{array}{c}-0.980^{* * *} \\
(0.477)\end{array}$ & $\begin{array}{c}0.123 \\
(0.654)\end{array}$ \\
\hline 0.85 & $516 \times 26$ & $\begin{array}{l}-0.344 \\
(0.474)\end{array}$ & $\begin{array}{c}-1.272^{\star * *} \\
(0.464)\end{array}$ & $\begin{array}{l}-0.034 \\
(0.648)\end{array}$ \\
\hline 0.9 & $516 \times 26$ & $\begin{array}{l}-0.344 \\
(0.474)\end{array}$ & $\begin{array}{c}-1.142^{* * *} \\
(0.428)\end{array}$ & $\begin{array}{l}-0.210 \\
(0.610)\end{array}$ \\
\hline
\end{tabular}

The table shows the average regression coefficient results of equation (2) using the simulated data of 516 agents with 26 bimonthly data points each after a burn-in period of 60 months with standard errors displayed in parentheses. The regression results are similar for different assumptions about the number of data points, initial savings levels, and time horizons. 
Table 8: Simulated Sophistication Regression Results - Equivalent to Empirical Setting

\begin{tabular}{|c|c|c|c|c|}
\hline & \multicolumn{4}{|c|}{ Sophistication Regression Coefficient $b_{3}$} \\
\hline & Obs. & standard & sophisticated & naïve \\
\hline \multicolumn{5}{|c|}{ Short-run Impatience $\boldsymbol{\beta}$} \\
\hline 0.6 & $516 \times 26$ & $\begin{array}{l}-0.103 \\
(0.208)\end{array}$ & $\begin{array}{c}-0.135^{\star * *} \\
(0.059)\end{array}$ & $\begin{array}{l}-0.050 \\
(0.102)\end{array}$ \\
\hline 0.65 & $516 \times 26$ & $\begin{array}{l}-0.103 \\
(0.208)\end{array}$ & $\begin{array}{c}-0.198^{\star * *} \\
(0.076)\end{array}$ & $\begin{array}{c}0.004 \\
(0.122)\end{array}$ \\
\hline 0.7 & $516 \times 26$ & $\begin{array}{l}-0.103 \\
(0.208)\end{array}$ & $\begin{array}{c}-0.281^{\star * *} \\
(0.097)\end{array}$ & $\begin{array}{c}0.045 \\
(0.134)\end{array}$ \\
\hline 0.75 & $516 \times 26$ & $\begin{array}{l}-0.103 \\
(0.208)\end{array}$ & $\begin{array}{c}-0.376^{* \star *} \\
(0.132)\end{array}$ & $\begin{array}{c}0.039 \\
(0.147)\end{array}$ \\
\hline 0.8 & $516 \times 26$ & $\begin{array}{l}-0.103 \\
(0.208)\end{array}$ & $\begin{array}{c}-0.409^{* * *} \\
(0.172)\end{array}$ & $\begin{array}{c}0.005 \\
(0.160)\end{array}$ \\
\hline 0.85 & $516 \times 26$ & $\begin{array}{l}-0.103 \\
(0.208)\end{array}$ & $\begin{array}{c}-0.384^{\star *} \\
(0.202)\end{array}$ & $\begin{array}{l}-0.036 \\
(0.172)\end{array}$ \\
\hline 0.9 & $516 \times 26$ & $\begin{array}{l}-0.103 \\
(0.208)\end{array}$ & $\begin{array}{l}-0.309^{*} \\
(0.219)\end{array}$ & $\begin{array}{l}-0.075 \\
(0.183)\end{array}$ \\
\hline
\end{tabular}

The table shows the average regression coefficient results of equation (3) using the simulated data of 516 agents with 26 bimonthly data points each after a burn-in period of 60 months with standard errors displayed in parentheses. The regression results are similar for different assumptions about the number of data points, initial savings levels, and time horizons. 
Table 9: Sensitivity Estimates

\begin{tabular}{|c|c|c|c|c|c|c|}
\hline & \multicolumn{6}{|c|}{ Sensitivity to Paycheck Receipt } \\
\hline & Obs. & Mean & Std. Dev. & $\begin{array}{l}\text { 25th } \\
\text { pctile }\end{array}$ & $\begin{array}{l}\text { 50th } \\
\text { pctile }\end{array}$ & $\begin{array}{l}\text { 75th } \\
\text { pctile }\end{array}$ \\
\hline \multicolumn{7}{|c|}{ Sensitivity - Pooled estimates } \\
\hline Short-Run Consumables & 516 & 0.061 & 0.009 & \multicolumn{3}{|l|}{ t-stat $=6.94$} \\
\hline Restaurants\&Entertainment & 526 & 0.047 & 0.008 & \multicolumn{2}{|l|}{ t-stat $=5.74$} & \\
\hline \multicolumn{7}{|c|}{ Sensitivity - Individual estimates } \\
\hline Short-Run Consumables & 516 & 0.061 & 0.211 & -0.081 & 0.049 & 0.199 \\
\hline Restaurants\&Entertainment & 516 & 0.046 & 0.201 & -0.086 & 0.052 & 0.172 \\
\hline \multicolumn{7}{|c|}{ Effect of Resources on Sensitivity ( \3) } \\
\hline Short-Run Consumables & 516 & -0.473 & 8.932 & -0.116 & 0.014 & 0.134 \\
\hline Restaurants\&Entertainment & 516 & 0.122 & 4.082 & -0.135 & 0.012 & 0.170 \\
\hline
\end{tabular}

The table shows summary statistics of the baseline estimates of each user's sensitivity to paycheck receipt and the effect of higher resources on this sensitivity. Sensitivity to paycheck receipt is captured by the coefficient on payweek in equation (4). The effect of higher resources on sensitivity is captured by the coefficient on payweek $*$ resources in equation (5). Both equations are estimated separately for each user and include day of week and month fixed effects. Resources are instrumented for with calculated balances based on regular payments. 
Table 10: Classification Into Sophisticated and Naive

\begin{tabular}{|c|c|c|c|}
\hline \multirow[b]{3}{*}{ Short-run Consumables } & \multicolumn{3}{|c|}{ Restaurant\&Entertainment } \\
\hline & Naïve & Sophisticated & Total \\
\hline & & & \\
\hline Naïve & 210 & 75 & 285 \\
\hline Sophisticated & 66 & 165 & 231 \\
\hline Total & 276 & 240 & 516 \\
\hline
\end{tabular}

This table shows the number of users classified as sophisticated or naive based on estimates using either short-run consumables or restaurant and entertainment spending. Users are classified as sophisticated if additional resources decrease sensitivity to paycheck receipt, i.e. if the coefficient on payweek $*$ resources in equation (5) is negative. 
Table 11: Summary Statistics by Sophistication

\begin{tabular}{|c|c|c|c|}
\hline & Naïve & Sophisticated & $\begin{array}{l}\text { t-test for equality } \\
(p \text {-value })\end{array}$ \\
\hline \multicolumn{4}{|c|}{ Sensitivity to Paycheck (Short-run Consumables) } \\
\hline Average sensitivity & 0.051 & 0.072 & 0.263 \\
\hline Median sensitivity & 0.043 & 0.059 & \\
\hline \multicolumn{4}{|c|}{ Sensitivity to Paycheck (Restaurant \& Entertainment) } \\
\hline Average sensitivity & 0.046 & 0.045 & 0.969 \\
\hline Median sensitivity & 0.058 & 0.034 & \\
\hline \multicolumn{4}{|l|}{ Income and Debt } \\
\hline Income - Mean & 3,808 & 3,802 & 0.975 \\
\hline Credit Card Debt - Mean & 14,144 & 13,693 & 0.713 \\
\hline Credit Card Debt - Median & 9,430 & 10,133 & \\
\hline Credit Card Debt / Income - Mean & 3.786 & 4.773 & 0.306 \\
\hline \multicolumn{4}{|l|}{ Total Discretionary Spending } \\
\hline avg. $\$$ & $1,844.0$ & $1,755.8$ & 0.307 \\
\hline avg. $\%$ of income & 52.9 & 51.6 & 0.598 \\
\hline avg. $\%$ spend on credit cards & 34.3 & 33.9 & 0.854 \\
\hline \multicolumn{4}{|l|}{ Short-run Consumables } \\
\hline avg. \$ - mean & 560.9 & 537.0 & 0.503 \\
\hline avg. $\%$ spend on credit cards & 31.1 & 31.1 & 0.981 \\
\hline \multicolumn{4}{|l|}{ Restaurant \& Entertainment } \\
\hline avg. \$ - mean & 298.6 & 282.6 & 0.289 \\
\hline avg. $\%$ spend on credit cards & 32.4 & 32.4 & 0.978 \\
\hline \multicolumn{4}{|l|}{ Planned Paydown - 90 Days } \\
\hline Mean & $2,540.1$ & $2,409.7$ & 0.574 \\
\hline Median & $1,795.1$ & $1,723.3$ & \\
\hline $\mathrm{N}$ & 285 & 231 & \\
\hline
\end{tabular}

The table shows summary statistics on estimated sensitivity to paycheck receipt, monthly income, debt and spending for users classified as naive or sophisticated based on estimates using short-run consumables. 
Table 12: Effect of Impatience and Planned Paydown on Actual Debt Paydown by Naive and Sophisticated Agents

\begin{tabular}{|c|c|c|}
\hline & \multicolumn{2}{|c|}{ Paydown } \\
\hline & 90 Days & 180 Days \\
\hline Sensitivity & $\begin{array}{c}8.511 \\
(7.253)\end{array}$ & $\begin{array}{l}6.461^{*} \\
(3.921)\end{array}$ \\
\hline Planned paydown & $\begin{array}{l}0.179^{*} \\
(0.094)\end{array}$ & $\begin{array}{c}0.129 \\
(0.086)\end{array}$ \\
\hline Sensitivity * Sophisticated & $\begin{array}{c}-33.293^{\star * *} \\
(11.638)\end{array}$ & $\begin{array}{c}-10.179^{*} \\
(5.861)\end{array}$ \\
\hline Planned paydown * Sophisticated & $\begin{array}{l}0.371^{*} \\
(0.224)\end{array}$ & $\begin{array}{l}0.391^{*} \\
(0.212)\end{array}$ \\
\hline Median paycheck (in 1,000s) & $\begin{array}{c}1.938 \\
(1.503)\end{array}$ & $\begin{array}{c}1.990^{*} \\
(1.150)\end{array}$ \\
\hline Original debt (in 1,000s) & $\begin{array}{c}0.173 \\
(0.123)\end{array}$ & $\begin{array}{l}-0.028 \\
(0.104)\end{array}$ \\
\hline Median paycheck * Sophisticated & $\begin{array}{l}-2.116 \\
(3.148)\end{array}$ & $\begin{array}{l}-2.412 \\
(2.280)\end{array}$ \\
\hline Original debt * Sophisticated & $\begin{array}{l}-0.346 \\
(0.273)\end{array}$ & $\begin{array}{l}-0.148 \\
(0.236)\end{array}$ \\
\hline Sophisticated & $\begin{array}{c}4.157 \\
(5.747)\end{array}$ & $\begin{array}{l}-1.099 \\
(4.271)\end{array}$ \\
\hline Constant & $\begin{array}{c}-12.035^{* * *} \\
(2.688)\end{array}$ & $\begin{array}{c}-8.585^{* * *} \\
(2.035)\end{array}$ \\
\hline Number of individuals & 516 & 516 \\
\hline
\end{tabular}

This table shows regression estimates of equation (6) with bootstrapped standard errors in parentheses. Variables are winsorized at the $1 \%$ level. Paydown is the average daily reduction in debt levels. Sensitivity is the coefficient $\gamma_{1}$ in equation (4). Users are classified as sophisticated if additional resources reduce the sensitivity to paycheck receipt and as naive otherwise. Significance levels: ${ }^{*}(p<0.10),{ }^{* *}(p<0.05),{ }^{* * *}(p<0.01)$. 


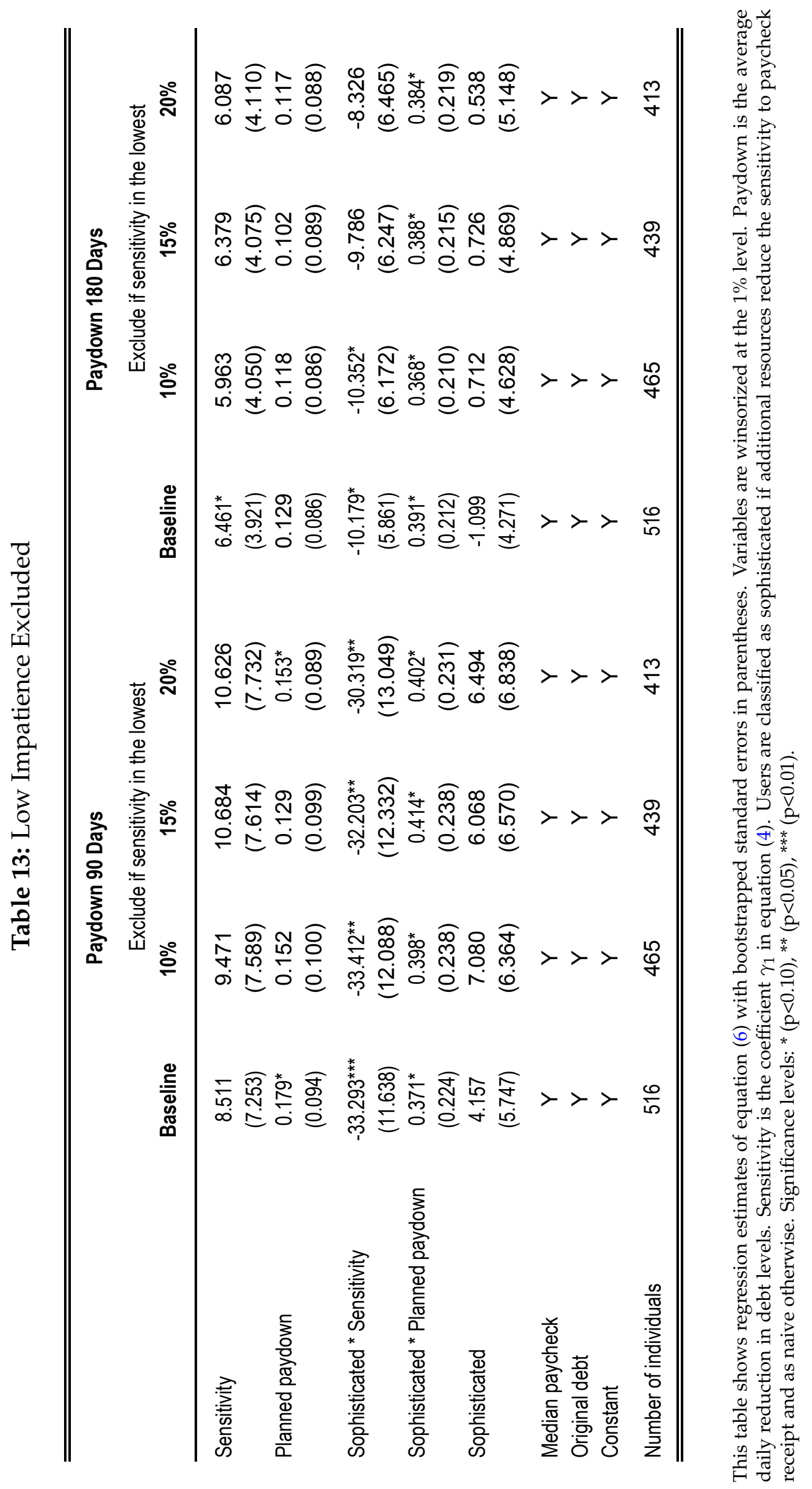


Table 14: Debt Paydown and Consumption Patterns - Different Restrictions on Sensitivity Estimates

\begin{tabular}{|c|c|c|c|c|}
\hline & baseline & buffer stock & $\begin{array}{l}\text { total discretionary } \\
\text { affordable }\end{array}$ & no restriction \\
\hline \multicolumn{5}{|c|}{ Dependent Variable: Paydown 90 Days } \\
\hline Sensitivity & $\begin{array}{c}8.511 \\
(7.253)\end{array}$ & $\begin{array}{c}6.135 \\
(6.823)\end{array}$ & $\begin{array}{c}8.934 \\
(6.330)\end{array}$ & $\begin{array}{l}8.362 \\
(6.833)\end{array}$ \\
\hline Planned paydown & $\begin{array}{l}0.179^{*} \\
(0.094)\end{array}$ & $\begin{array}{l}0.180^{*} \\
(0.095)\end{array}$ & $\begin{array}{l}0.180^{*} \\
(0.095)\end{array}$ & $\begin{array}{l}0.179^{*} \\
(0.102)\end{array}$ \\
\hline $\begin{array}{l}\text { Sensitivity } \\
\text { * Sophisticated }\end{array}$ & $\begin{array}{c}-33.293^{* * *} \\
(11.638)\end{array}$ & $\begin{array}{c}-28.158^{* * *} \\
(11.372)\end{array}$ & $\begin{array}{c}-31.647^{\star * *} \\
(10.381)\end{array}$ & $\begin{array}{l}-32.144^{* * *} \\
(11.634)\end{array}$ \\
\hline $\begin{array}{l}\text { Planned paydown } \\
\text { * Sophisticated }\end{array}$ & $\begin{array}{l}0.371^{*} \\
(0.224)\end{array}$ & $\begin{array}{l}0.380^{*} \\
(0.228)\end{array}$ & $\begin{array}{l}0.372^{*} \\
(0.226)\end{array}$ & $\begin{array}{c}0.368 \\
(0.224)\end{array}$ \\
\hline Sophisticated & $\begin{array}{c}4.157 \\
(5.747)\end{array}$ & $\begin{array}{l}3.061 \\
(5.632)\end{array}$ & $\begin{array}{c}3.610 \\
(5.740)\end{array}$ & $\begin{array}{c}4.394 \\
(5.232)\end{array}$ \\
\hline \multicolumn{5}{|c|}{ Dependent Variable: Paydown 180 Days } \\
\hline Sensitivity & $\begin{array}{l}6.461^{*} \\
(3.921)\end{array}$ & $\begin{array}{c}4.428 \\
(4.065)\end{array}$ & $\begin{array}{l}3.920 \\
(3.988)\end{array}$ & $\begin{array}{l}5.593 \\
(3.655)\end{array}$ \\
\hline Planned paydown & $\begin{array}{c}0.129 \\
(0.086)\end{array}$ & $\begin{array}{l}0.139 \\
0.094\end{array}$ & $\begin{array}{l}0.139 \\
0.093\end{array}$ & $\begin{array}{l}0.139^{*} \\
(0.093)\end{array}$ \\
\hline $\begin{array}{l}\text { Sensitivity } \\
\text { * Sophisticated } \\
\text { Planned paydown } \\
\text { * Sophisticated }\end{array}$ & $\begin{array}{c}-10.179^{*} \\
(5.861) \\
0.391^{*} \\
(0.212)\end{array}$ & $\begin{array}{l}-8.115 \\
(6.876) \\
0.420^{*} \\
(0.232)\end{array}$ & $\begin{array}{l}-6.921 \\
(6.289) \\
0.418^{*} \\
(0.232)\end{array}$ & $\begin{array}{l}-8.567 \\
(5.653) \\
0.416^{*} \\
(0.225)\end{array}$ \\
\hline Sophisticated & $\begin{array}{l}-1.099 \\
(4.271)\end{array}$ & $\begin{array}{l}-1.455 \\
(4.322)\end{array}$ & $\begin{array}{l}-1.550 \\
(4.373)\end{array}$ & $\begin{array}{l}-1.260 \\
(4.299)\end{array}$ \\
\hline \multicolumn{5}{|l|}{ Controls } \\
\hline Median Paycheck & Y & Y & Y & Y \\
\hline Original Debt & Y & Y & Y & Y \\
\hline Nr of individuals & 516 & 516 & 516 & 516 \\
\hline
\end{tabular}

This table shows regression estimates of equation (6) with bootstrapped standard errors in parentheses. Variables are winsorized at the $1 \%$ level. Paydown is the average daily reduction in debt levels. Sensitivity is the coefficient $\gamma_{1}$ in equation (4). Users are classified as sophisticated if additional resources reduce the sensitivity to paycheck receipt and as naive otherwise. Significance levels: ${ }^{*}(\mathrm{p}<0.10),{ }^{* *}(\mathrm{p}<0.05),{ }^{* * *}(\mathrm{p}<0.01)$. 


\section{A Estimating Sensitivity to Paycheck Receipt}

\section{A.1 Distribution of Estimated Sensitivities}

Figure A1 plots the distribution of the estimated sensitivity to paycheck receipt of expenditures on short-run consumables in the left panel, and of expenditures on restaurant and entertainment only in the right panel. The plot complements the summary statistics on the estimated sensitivity to paycheck receipt in Table 9. As indicated by the summary statistics, the mean of the distributions is shifted upwards from zero. A t-test confirms that it is significantly different from zero - that is the average user's expenditures react substantially to paycheck arrival. The two distributions also look very similar irrespective of whether expenditures on short-run consumables or restaurant and entertainment only were considered.

\section{A.2 Hypothetical Balances Based on Regular Payments}

Section 4.2.2 estimates the effect of changing resources on the sensitivity to paycheck receipt. To do so, we isolate the variation in resources uncorrelated with an individual's prior spending by calculating hypothetical balances for each consumer. Figure A2 illustrates the construction of these hypothetical balances. It shows actual (upper panel) and calculated balances (lower panel) for a hypothetical consumer who receives regular bi-weekly paychecks (illustrated by upward pointing arrows) and has to pay rent monthly every other pay date (downward pointing red arrows). The upper panel shows the agent's actual balances given his income, rent payments, and spending patterns. The lower panel shows the agent's calculated balances. Instead of using the agent's actual spending, non-regular spending is assumed to be split equally across all days. Each day's balance is then calculated based on the agent's regular paycheck, regular rent payment, and average daily spending. The figure shows that the monthly regular rent payments lead to substantially lower resources during the pay cycle in which they have to be made compared to the pay cycle where no regular payment is due. The calculated balances isolate this exogenous variation in the agent's level of resources from the endogenous variation caused by prior discretionary spending.

\section{A.3 Sensitivity to Paycheck Under Different Restrictions}

Table A1 shows summary statistics of estimated sensitivity to paycheck under different restrictions in the top panel and the intra user correlation between these estimates in the bottom panel. The estimated sensitivity decreases as more pay cycles are filtered out in which the user may have been credit constrained. However, the estimated sensitivity would decrease even if credit constraints did not play any role, since the excluded pay cycles are those with the highest spending. On the individual level, the estimated sensitivities are highly correlated. Within a given consumption category (shortrun consumables or restaurant and entertainment), the correlation between sensitivity estimates with

different restrictions is more than $90 \%$. Across the two spending categories, the estimates are also similar with correlations between $55 \%$ and $65 \%$.

\section{A.4 Planned Paydown by Differences in Consumption Patterns}

Table A2 shows that planned paydown is similarly influenced by characteristics for naive and sophisticated individuals. There is no statistically significant effect of sensitivity or sophistication on planned paydown. Overall, planned paydown seems to be determined primarily by factors such as income, 
existing debt levels and possible other considerations such as spending needs and ease of reductions in spending.

\section{B Robustness of Paydown Results}

\section{B.1 Estimates based on Restaurant and Entertainment Spending and Regression Specifi- cation}

The first two columns of Table A3 show estimates of equation (6) when the sensitivity and sophistication are based only on spending on restaurant and entertainment rather than the broader category of short-run consumables. The last six columns of Table A3 show different regression specifications of the baseline results in Table 12. Unlike in the baseline, the control variables are assumed to have the same effect for both types of agents and are therefore not interacted with sophistication. In addition, the effect of sensitivity and planned paydown is estimated separately. To do so, either sensitivity to paycheck or planned paydown is interacted with sophistication and the respective other variable is only included as a control (not interacted with sophistication). The results for each variable are very similar to the baseline results in Table 12.

\section{B.2 Direct Relationship between Paydown and Consumption Patterns}

To estimate any direct relation between the reduction in sensitivity to paycheck receipt and debt paydown, we estimate the following regression equation:

$$
\text { Paydown }_{i}=\mu_{0}+(\text { coefficient_on_payweek } * \text { resources }) \mu_{1}+X_{i}^{\prime} \lambda+v_{i}
$$

The regressor of interest is (coefficient_on_payweek $*$ resources) estimated in equation (5), which captures how additional resources affect an agent's sensitivity to paycheck receipt. Equation (A1) is estimated with and without including the explanatory variables from the baseline specification (equation (6)) as additional controls. Table A4 shows that the direct relationship between paydown and the reduction in sensitivity with additional resources is weak in all specifications. None of the coefficients is statistically significant and several are positive. That is the opposite of what would be expected under the hypothesis that a reduction in sensitivity as resources increase directly leads to higher debt paydown.

\section{B.3 Sensitivity Estimates Based on Level of Spending and Weekly Spending}

To be included in the baseline sample, users are required to have at least 45 days of positive spending. Table A5 replicates the baseline results requiring either 40 or 50 days of positive spending instead. Throughout, the results are very similar to the baseline estimates in Table 12.

In the baseline specification, spending is measured in logs and on a daily level. Instead, the first two columns of Table A6 use sensitivity estimates based on the actual amount spent and normalizes those estimates by average spending (levels instead of logs). The third and fourth columns use weekly spending instead of daily spending. The last two columns use sensitivity estimates based only on debit card spending, excluding any spending on credit cards. Some users do not have enough spending on debit cards, so the sample is smaller - 494 instead of 516 users. All results are very similar to the baseline estimates in Table 12. 


\section{B.4 Robustness to Sophistication Classification}

The first four columns of Table A7 exclude users who get classified differently into naive and sophisticated based on short-run consumables or restaurant and entertainment spending. This reduces the sample size, increasing standard errors so that some of the estimates are just outside standard significance bounds. Overall, the results are similar to the baseline results in Table 12. If anything, the point estimates are more similar across categories, supporting the notion that previously misclassified users lead to additional noise in the estimation. The last four columns of Table A7 classify users as sophisticated or naive based on OLS estimates of the effect of resources instead of using estimates when resources are instrumented for by hypothetical balances as outlined in Section 4.2. If the endogeneity concern motivating the use of IV estimates is important, we would expect a substantial number of users to be misclassified when using OLS estimates and, hence, to find fewer differences between the two groups. Indeed, Table A7 finds smaller difference between sophisticated and naive, which are mostly not statistically significant, reinforcing the need to instrument for the level of resources.

\section{Data Preparation and Classifications}

\section{C.1 Sample Selection}

The following table illustrates how many users are lost at each step of the data selection process, starting with a random sample of users. We allow users to fulfill all sample criteria in 4 possible ways. First, they are included when all criteria are fulfilled considering all available data. Next, we restrict each user's data to one year, 270 days, and 180 days after sign-up and include them if they fulfill all criteria during this shorter sample horizon. This includes users who acquire additional accounts later in the sample or switch jobs, such that they miss more than one paycheck or no longer have a regular paycheck later in the sample. The vast majority of users, 470 out of 516 fulfill the sample criteria when all their data are considered. 


\begin{tabular}{lc}
\hline \hline Users with a linked checking account in original sample & 3653 \\
and observed for at least 180 days after sign-up & 2558 \\
and all accounts linked at sign-up & 2051 \\
and a credit card and plan to reduce debt & 1845 \\
and at least one paycheck deposited into a checking account & 1590 \\
and regular bi-weekly paychecks & 1118 \\
and regular paychecks account for more than 70\% of all income & 923 \\
and appear to have all relevant accounts linked & 897 \\
and at least 8 regular, non-constrained paycycles & 698 \\
and at least 45 days of positive spending & 579 \\
and fulfill all above criteria over the same horizon & 516 \\
fulfill criteria over full time observed & 470 \\
fulfill criteria during first year observed & 21 \\
fulfill criteria during first 270 days observed & 12 \\
\hline \hline
\end{tabular}

\section{C.2 Classifying Transactions}

The transaction data used in the paper includes the amount, date charged and description the customer sees on his bank account statement, as well as a code from the data provider which classifies transactions into different categories. Based on this information, we first identify transactions which are likely to be paychecks. The remaining transactions are classified as either regular or non-regular. Finally, we define two additional types of spending, short-run consumables and total discretionary spending. This online appendix explains how transactions are classified into each category.

Paychecks Transactions are identified as paychecks when they are classified as such by the data provider or when their description contains one or more of the following words or word groups:

• "Payroll”, "payroll”, "PAYROLL", "PAYRLL", "PAYROL”, “PAYPPD”

- "SALARY", "salary”, "Salary”, "FED SAL"

- "PPD", plus one of the following: "DIR DEP", "DIRDEP", “DIRECTDEPOSIT", "DIRECT DEPOSIT", “DIRECT DEP", “DIR.DEPST", “CO ID”, "PAYMENTPPD”

- "CO ID" and "INDN", plus one of following: "DIR DEP", “DIRDEP", "DIRECTDEPOSIT", "DIRECT DEPOSIT", "DIRECT DEP"

Even if they meet the above criteria, transactions are not classified as a paycheck if they contain any of the following words: 
- "tax", “Tax", “TAX”

- "PAYPAL", "paypal”, "HALF.COM", "Square Inc”, "SQUARE INC"

Finally, we classify regular deposits (identified the same way as regular payments described below) of more than $\$ 500$ as paychecks.

Spending We first distinguish between regular and non-regular payments. Non-regular payments are further distinguished into discretionary spending and non-regular, non-discretionary spending. Discretionary spending is defined as an expense where at the time of the payment the consumer had discretion about i) whether to incur the payment at all, or ii) how much to spend. Payments are classified as discretionary based on the type of expenditure category. An example of discretionary spending is a restaurant meal. For non-discretionary spending, such as are cell phone bills or utility bills, the amount due depends on past consumption, but there is no discretion once the bill arrives. we further consider short-run consumables, a subcategory of discretionary spending described below.

Regular Payments To classify transactions as regular payments they are first grouped into sets which have the same

- exact amount

- amount when cents are truncated

- amount rounded to the next integer

- amount rounded to multiples of $\$ 10$ when the transaction amount is more than $\$ 100$

A set of transactions is classified as occurring regularly every two weeks if

- there are at least 7 transactions

- the median difference between payments is between 13 and 16 days

- at most one payment in the sequence was missed, i.e. the maximum amount of time between payments is 31 days

A set of transactions is classified as occurring regularly monthly if

- there are at least 5 transactions

- the median difference between payments is between 28 and 31 days

- at most one payment in the sequence was missed, i.e. the maximum amount of time between payments is 64 days

Non-regular payments are further classified into short-run consumables, non-durables or total discretionary spending. These three broad categories consist of the following sub-categories as assigned by the data provider:

- Short-run Consumables 
- gasoline/fuel

- groceries

- restaurant/dining

- entertainment (movie tickets, Netflix, iTunes, video/DVD rental, computer games, party stores, etc.)

- Total discretionary expenditure

- short-run consumables

- travel

- gifts

- drugstore purchases/personal care

- pet expenditures

- general merchandise (Target, Walmart, Cosco, etc.)

- automotive expenditures (excluding car purchases), primarily oil checks and the like

- toys and other children's products

- clothing and shoes

- healthcare/medical products

- home maintenance

- non-regular cable and online services

- hobby expenditures

- electronics

- credit reports or services

- advertising or custom management services

- non-regular bills

- PayPal purchases

- unclassified credit card purchases

- non-regular uncategorized transactions 
Figure A1: Distribution of Individual-Level Sensitivity to Paycheck Receipt
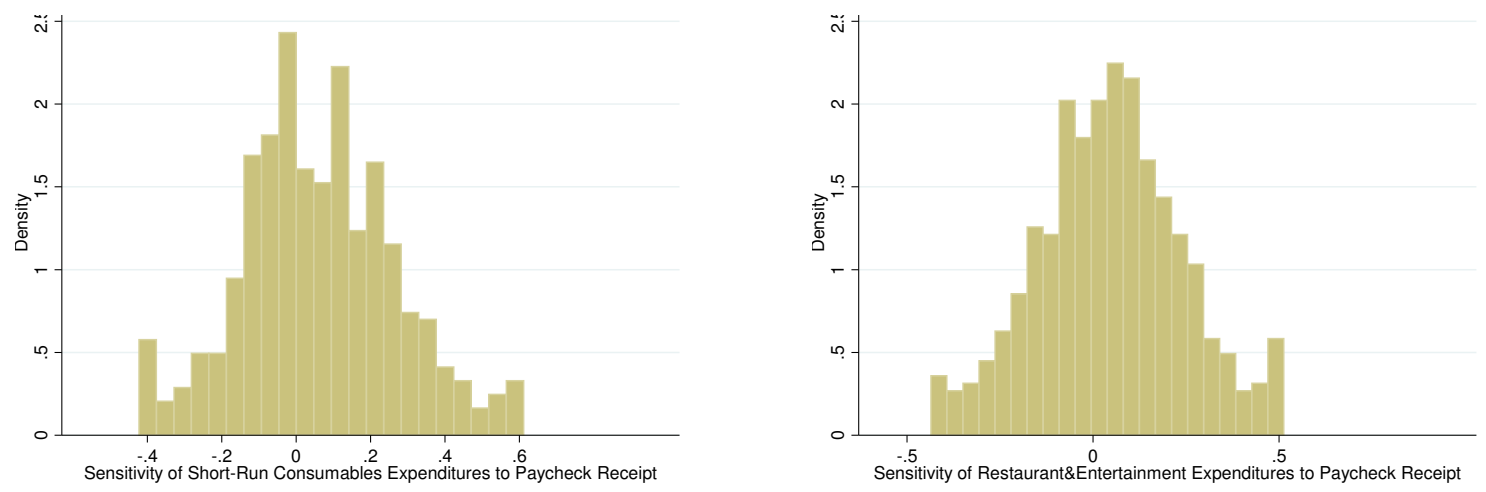

The distribution of the estimates of each user's sensitivity to paycheck receipt, captured by $\gamma_{1 i}$ in equation (4). 


\section{Figure A2: Hypothetical Balances Based on Regular Payments}
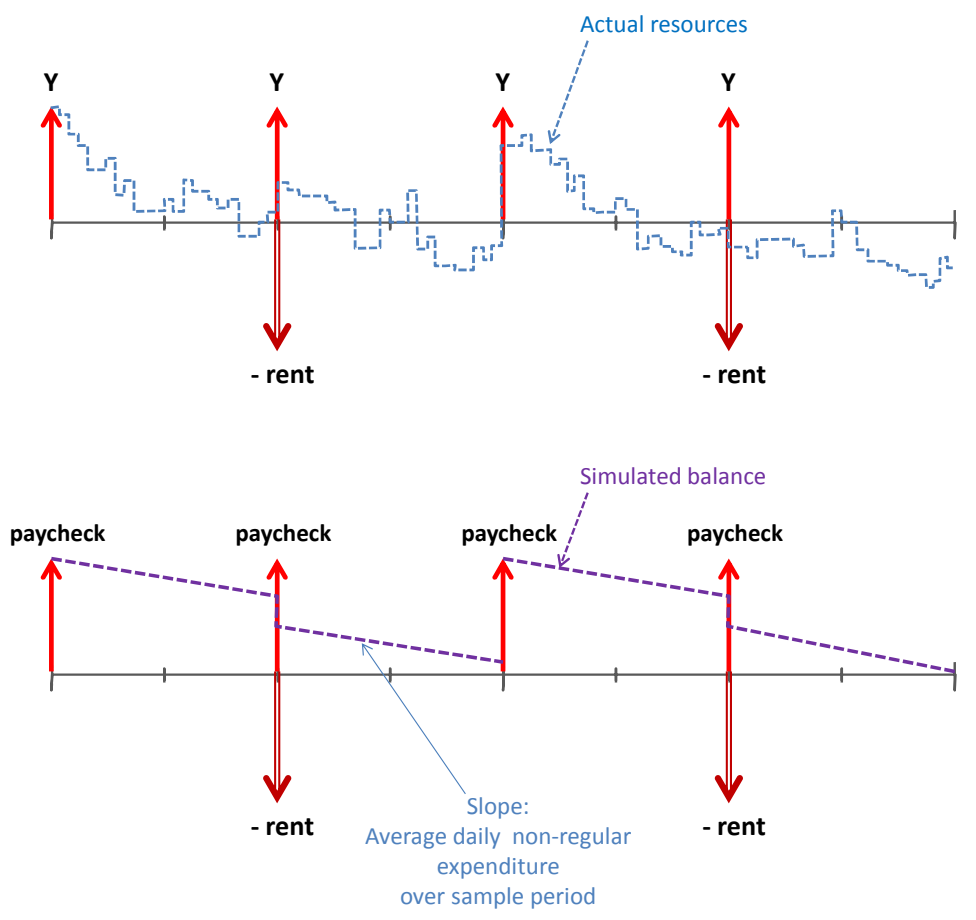

The figure illustrates the construction of hypothetical balances based on regular payments. The upper panel shows actual balances for a hypothetical agent who receives regular bi-weekly paychecks (illustrated by upward pointing red arrows) and has to pay rent monthly every other pay date (downward pointing red arrows). The lower panel shows the agent's hypothetical balances based on regular payments and the assumption that spending is split equally across all days. Each day's balance is calculated based on the agent's regular paycheck, regular rent payment and average daily spending. 
Table A1: Sensitivity Estimates under Different Restrictions

Panel A: Sensitivity Estimates

\begin{tabular}{lcccccc}
\hline \hline & \multicolumn{5}{c}{ Sensitivity to Paycheck Receipt } \\
& Obs. & Mean & Std. Dev. & 25th pctile & 50th pctile & 75th pctile \\
\hline Short-run Consumables & & & & & & \\
\hline no restriction & 516 & 0.074 & 0.211 & -0.064 & 0.066 & 0.201 \\
category spending possible (baseline) & & 0.061 & 0.211 & -0.081 & 0.049 & 0.199 \\
buffer stock (5th percentile) & & 0.052 & 0.227 & -0.093 & 0.040 & 0.190 \\
total discretionary possible & & 0.057 & 0.216 & -0.089 & 0.039 & 0.198 \\
Restaurants\&Entertainment & & & & & & \\
\hline no restriction & 516 & 0.056 & 0.201 & -0.070 & 0.056 & 0.192 \\
category spending possible (baseline) & & 0.046 & 0.201 & -0.086 & 0.052 & 0.172 \\
buffer stock (5th percentile) & & 0.041 & 0.223 & -0.108 & 0.050 & 0.179 \\
total discretionary possible & & 0.040 & 0.206 & -0.089 & 0.042 & 0.163 \\
\hline \hline
\end{tabular}

\section{Panel B: Correlation}

\begin{tabular}{|c|c|c|c|c|c|c|c|c|}
\hline & \multicolumn{4}{|c|}{ Short-run Consumables } & \multicolumn{4}{|c|}{ Restaurant\&Entertainment } \\
\hline & $\begin{array}{c}\text { no } \\
\text { restriction }\end{array}$ & $\begin{array}{l}\text { category s } \\
\text { baseline }\end{array}$ & $\begin{array}{l}\text { spending } \\
\text { with buffer }\end{array}$ & $\begin{array}{c}\text { total } \\
\text { possible }\end{array}$ & $\begin{array}{c}\text { no } \\
\text { restriction }\end{array}$ & $\begin{array}{l}\text { category } \\
\text { baseline }\end{array}$ & $\begin{array}{l}\text { spending } \\
\text { with buffer }\end{array}$ & $\begin{array}{c}\text { total } \\
\text { possible }\end{array}$ \\
\hline \multicolumn{9}{|l|}{ Short-run Consumables } \\
\hline no restriction & 1 & & & & & & & \\
\hline category spending (baseline) & 0.976 & 1 & & & & & & \\
\hline category spending with buffer & 0.903 & 0.927 & 1 & & & & & \\
\hline total discretionary possible & 0.948 & 0.964 & 0.933 & 1 & & & & \\
\hline \multicolumn{9}{|l|}{ Restaurant\&Entertainment } \\
\hline no restriction & 0.648 & 0.628 & 0.584 & 0.614 & 1 & & & \\
\hline category spending (baseline) & 0.629 & 0.632 & 0.587 & 0.617 & 0.983 & 1 & & \\
\hline category spending with buffer & 0.553 & 0.564 & 0.624 & 0.574 & 0.885 & 0.900 & 1 & \\
\hline total discretionary possible & 0.580 & 0.586 & 0.575 & 0.623 & 0.933 & 0.951 & 0.910 & 1 \\
\hline
\end{tabular}

The top panel shows summary statistics of each user's estimated sensitivity to paycheck receipt under restrictions other than the baseline estimates. The bottom panel shows the correlation between these estimates of each user's sensitivity to paycheck receipt. Throughout the table, the first row shows sensitivity estimates based on all paycycles the user is observed. The second row shows the baseline estimates. The third row requires payweek spending in each category to have been affordable without reducing the user's resources below the $5^{\text {th }}$ percentile of the user's observed resources. The fourth row requires total discretionary spending (rather than just spending in the respective category) to have been affordable. As in the baseline specification, sensitivity to paycheck receipt is captured by the coefficient on payweek in equation (4). 
Table A2: Sensitivity, Sophistication, and Planned Paydown

\begin{tabular}{|c|c|c|}
\hline & \multicolumn{2}{|c|}{ Planned Paydown } \\
\hline & Short-run Consumables & $\begin{array}{c}\text { Restaurant\& } \\
\text { Entertainment }\end{array}$ \\
\hline Sensitivity & $\begin{array}{c}145.538 \\
(131.181)\end{array}$ & $\begin{array}{c}186.976 \\
(170.901)\end{array}$ \\
\hline Sophisticated & $\begin{array}{c}32.648 \\
(113.646)\end{array}$ & $\begin{array}{c}140.571 \\
(104.431)\end{array}$ \\
\hline Sensitivity * Sophisticated & $\begin{array}{c}-70.542 \\
(246.732)\end{array}$ & $\begin{array}{l}-126.329 \\
(249.622)\end{array}$ \\
\hline Median paycheck (\$) & $\begin{array}{l}194.5^{\star * *} \\
(51.312)\end{array}$ & $\begin{array}{l}257.5^{\star * *} \\
(55.614)\end{array}$ \\
\hline Original debt (\$) & $\begin{array}{l}17.8^{* * *} \\
(3.309)\end{array}$ & $\begin{array}{l}15.8^{* * *} \\
(3.317)\end{array}$ \\
\hline Cash balances & $\begin{array}{c}3.247 \\
(4.462)\end{array}$ & $\begin{array}{c}2.283 \\
(4.485)\end{array}$ \\
\hline Available credit & $\begin{array}{c}2.435 \\
(2.116)\end{array}$ & $\begin{array}{c}3.641 \\
(2.779)\end{array}$ \\
\hline Median paycheck * Sophisticated & $\begin{array}{l}-2.058 \\
(76.658)\end{array}$ & $\begin{array}{l}-112.168 \\
(74.710)\end{array}$ \\
\hline Original debt * Sophisticated & $\begin{array}{c}1.296 \\
(4.541)\end{array}$ & $\begin{array}{c}4.279 \\
(4.553)\end{array}$ \\
\hline Cash balances * Sophisticated & $\begin{array}{l}-4.209 \\
(6.642)\end{array}$ & $\begin{array}{l}-1.390 \\
(6.632)\end{array}$ \\
\hline Available credit * Sophisticated & $\begin{array}{c}0.327 \\
(3.786)\end{array}$ & $\begin{array}{l}-1.986 \\
(3.552)\end{array}$ \\
\hline Constant & $\begin{array}{l}-123.076 \\
(113.267)\end{array}$ & $\begin{array}{l}-198.269 \\
(128.905)\end{array}$ \\
\hline Number of individuals & 516 & 516 \\
\hline
\end{tabular}

The table shows estimates of the effect of short-run impatience and sophistication on planned paydown with bootstrapped standard errors in parentheses. All variables are winsorized at the $1 \%$ level. Short-run impatience is measured as the coefficient $\beta_{1}$ in equation (4) using expenditures on short-run consumables or restaurant and entertainment as the dependent variable. Median paycheck and level of original debt are measured in dollars. Users are classified as sophisticated if additional resources reduce the sensitivity to paycheck receipt and as naive otherwise. Significance levels: ${ }^{*}(\mathrm{p}<0.10),{ }^{* *}(\mathrm{p}<0.05)$, $* * *(p<0.01)$. 


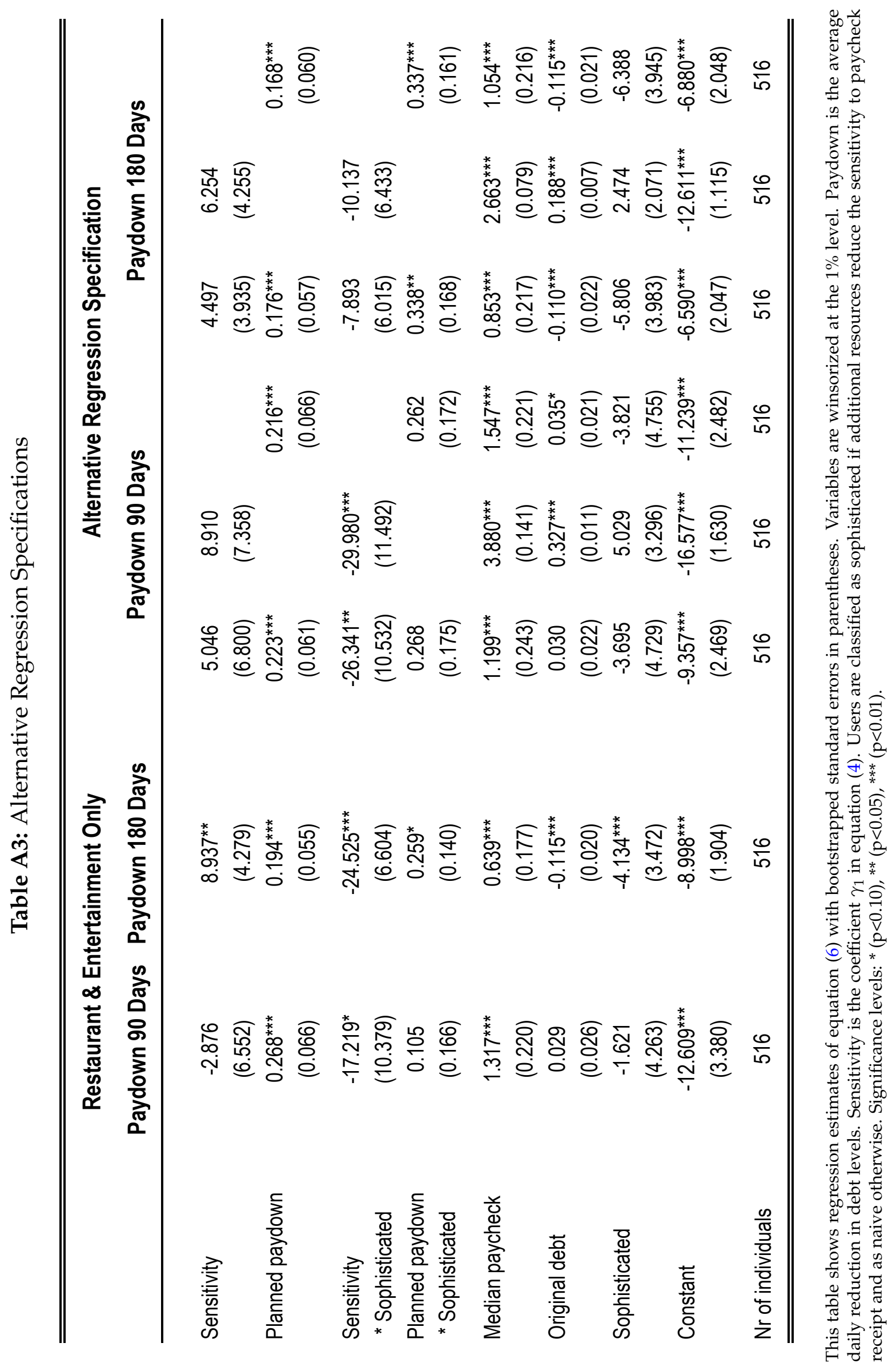


Table A4: Direct Effect of Sophistication Measure on Debt Paydown

\begin{tabular}{|c|c|c|c|c|c|c|c|c|}
\hline & \multicolumn{4}{|c|}{ Paydown 90 Days } & \multicolumn{4}{|c|}{ Paydown 180 Days } \\
\hline & I & ॥ & III & IV & V & $\mathrm{VI}$ & VII & VIII \\
\hline \multicolumn{9}{|c|}{ Short-run Consumables } \\
\hline Coefficient on & -0.439 & 0.114 & -0.224 & 0.683 & -0.497 & -0.539 & -0.376 & -0.075 \\
\hline ResourcesPayweek & $(0.432)$ & $(0.935)$ & $(0.675)$ & $(0.602)$ & $(0.145)$ & $(0.551)$ & $(0.238)$ & $(0.927)$ \\
\hline Winsorized & $1 \%$ & $5 \%$ & $1 \%$ & $5 \%$ & $1 \%$ & $5 \%$ & $1 \%$ & $5 \%$ \\
\hline Controls & & & $\mathrm{Y}$ & $\mathrm{Y}$ & & & $\mathrm{Y}$ & $\mathrm{Y}$ \\
\hline N & \multicolumn{8}{|c|}{516} \\
\hline 75th - 25th percentile & \multicolumn{8}{|c|}{0.251} \\
\hline \multicolumn{9}{|c|}{ Restaurant \& Entertainment } \\
\hline Coefficient on & -0.070 & 0.185 & -0.075 & 0.492 & 0.320 & 0.843 & 0.267 & 0.925 \\
\hline Resources*Payweek & $(0.864)$ & $(0.867)$ & $(0.847)$ & $(0.643)$ & $(0.218)$ & $(0.182)$ & $(0.271)$ & $(0.118)$ \\
\hline Winsorized & $1 \%$ & $5 \%$ & $1 \%$ & $5 \%$ & $1 \%$ & $5 \%$ & $1 \%$ & $5 \%$ \\
\hline Controls & & & $\mathrm{Y}$ & Y & & & $\mathrm{Y}$ & $Y$ \\
\hline $\mathrm{N}$ & \multicolumn{8}{|c|}{516} \\
\hline 75th - 25th percentile & \multicolumn{8}{|c|}{0.305} \\
\hline
\end{tabular}

The table shows regression estimates of equation (A1) with p-values based on bootstrapped standard errors in parentheses. The coefficient on the interaction of payweek and resources is estimated in equation (5). Full controls include all regressors included in equation (6), i.e., debt levels at sign up and user's monthly income. Significance levels: ${ }^{*}(\mathrm{p}<0.10),{ }^{* *}(\mathrm{p}<0.05)$, $* * * *(\mathrm{p}<0.01)$. 
Table A5: Paydown - Different Requirements for Days Observed for Sample Inclusion

\begin{tabular}{lcccccc}
\hline \hline & \multicolumn{3}{c}{ Paydown 90 Days } & \multicolumn{3}{c}{ Paydown 180 Days } \\
& Baseline & 40 obs & $\mathbf{5 0}$ obs & $\begin{array}{c}\text { Baseline } \\
\text { (45 obs) }\end{array}$ & $\mathbf{4 0}$ obs & $\mathbf{5 0}$ obs \\
\hline Sensitivity & $\mathbf{4 5}$ obs) & & & & & \\
& 8.511 & 8.260 & 2.825 & $6.461^{*}$ & 5.813 & 4.290 \\
Planned paydown & $(7.253)$ & $(6.831)$ & $(7.876)$ & $(3.921)$ & $(3.961)$ & $(4.296)$ \\
& $0.179^{*}$ & $0.180^{*}$ & $0.178^{*}$ & 0.129 & 0.103 & 0.127 \\
Sensitivity & $(0.094)$ & $(0.093)$ & $(0.094)$ & $(0.086)$ & $(0.084)$ & $(0.086)$ \\
* Sophisticated & $-33.293^{* * *}$ & $-31.175^{* * *}$ & $-32.280^{* * *}$ & $-10.179^{*}$ & -7.222 & $-10.515^{*}$ \\
Planned paydown & $(11.638)$ & $(10.972)$ & $(12.504)$ & $(5.861)$ & $(5.531)$ & $(6.358)$ \\
* Sophisticated & $0.371^{*}$ & 0.360 & $0.380^{*}$ & $0.391^{*}$ & $0.408^{* *}$ & $0.401^{*}$ \\
Median paycheck & $(0.224)$ & $(0.222)$ & $(0.227)$ & $(0.212)$ & $(0.208)$ & $(0.213)$ \\
& 1.938 & 1.817 & 1.752 & $1.990^{*}$ & 1.015 & $1.804^{*}$ \\
Original debt & $(1.503)$ & $(1.413)$ & $(1.572)$ & $(1.150)$ & $(1.149)$ & $(1.202)$ \\
& 0.173 & 0.177 & 0.187 & -0.028 & 0.102 & -0.029 \\
Median paycheck & $(0.123)$ & $(0.116)$ & $(0.126)$ & $(0.104)$ & $(0.111)$ & $(0.106)$ \\
* Sophisticated & -2.116 & -1.083 & -2.564 & -2.412 & -0.944 & -2.571 \\
Original debt & $(3.148)$ & $(2.923)$ & $(3.365)$ & $(2.280)$ & $(2.296)$ & $(2.399)$ \\
* Sophisticated & -0.346 & -0.337 & -0.358 & -0.148 & -0.244 & -0.150 \\
Sophisticated & $(0.273)$ & $(0.255)$ & $(0.278)$ & $(0.236)$ & $(0.250)$ & $(0.238)$ \\
& 4.157 & 2.728 & 4.664 & -1.099 & -3.063 & -1.211 \\
Constant & $(5.747)$ & $(5.444)$ & $(6.071)$ & $(4.271)$ & $(4.181)$ & $(4.545)$ \\
& $-12.035^{* * *}$ & $-12.105^{* * *}$ & $12.622^{* * *}$ & $-8.585^{* * *}$ & $-8.012^{* * *}$ & 0.607 \\
& $(2.688)$ & $(2.626)$ & $(2.801)$ & $(2.035)$ & $(2.005)$ & $(1.888)$ \\
Number of individuals & & & & & & \\
& 516 & 537 & 493 & 516 & 537 & 493 \\
\hline \hline
\end{tabular}

This table shows regression estimates of equation (6) with bootstrapped standard errors in parentheses. Variables are winsorized at the $1 \%$ level. Paydown is the average daily reduction in debt levels. Sensitivity is the coefficient $\gamma_{1}$ in equation (4). Users are classified as sophisticated if additional resources reduce the sensitivity to paycheck receipt and as naive otherwise. Significance levels: ${ }^{*}(\mathrm{p}<0.10),{ }^{* *}(\mathrm{p}<0.05),{ }^{* * *}(\mathrm{p}<0.01)$. 


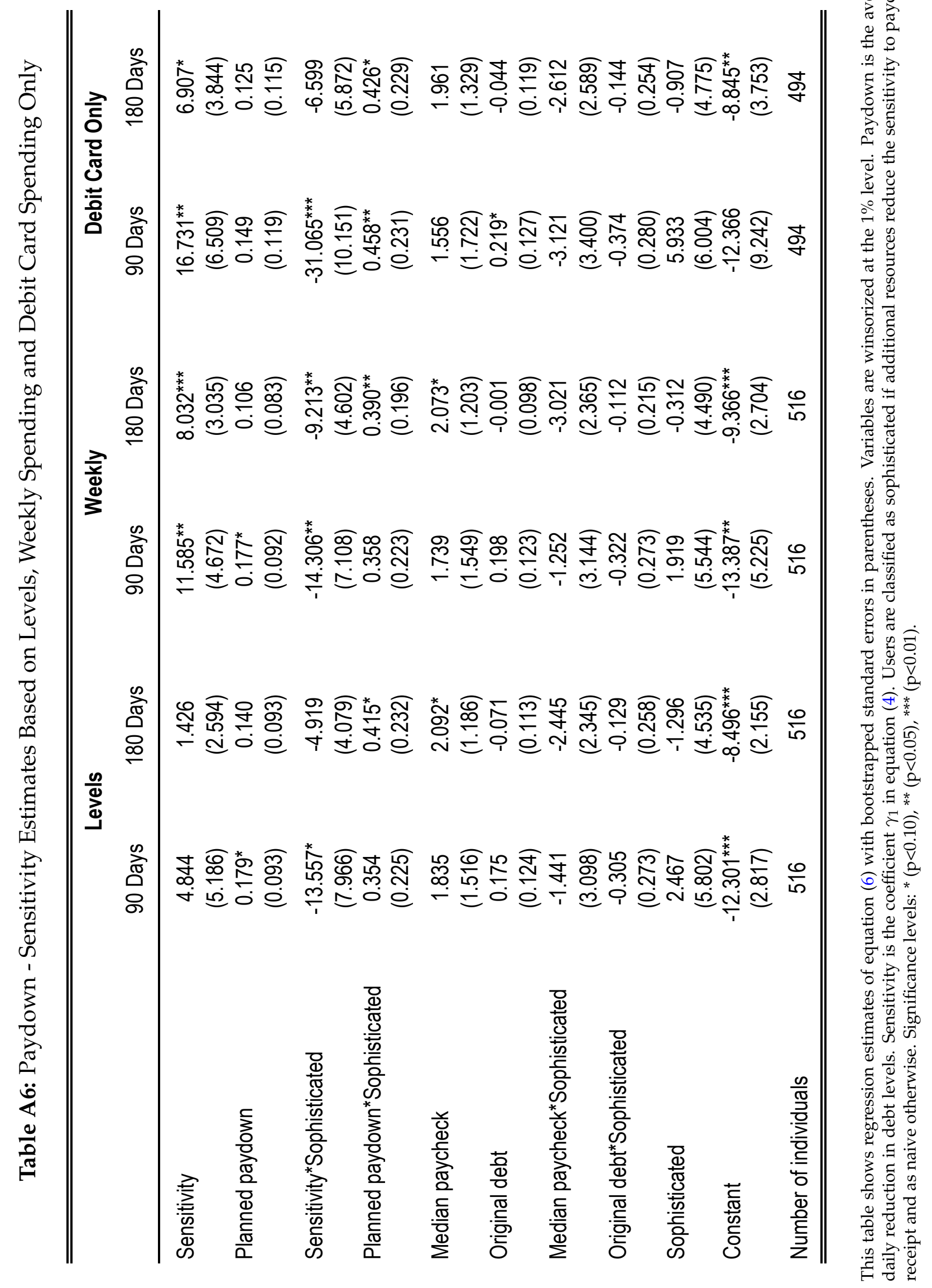




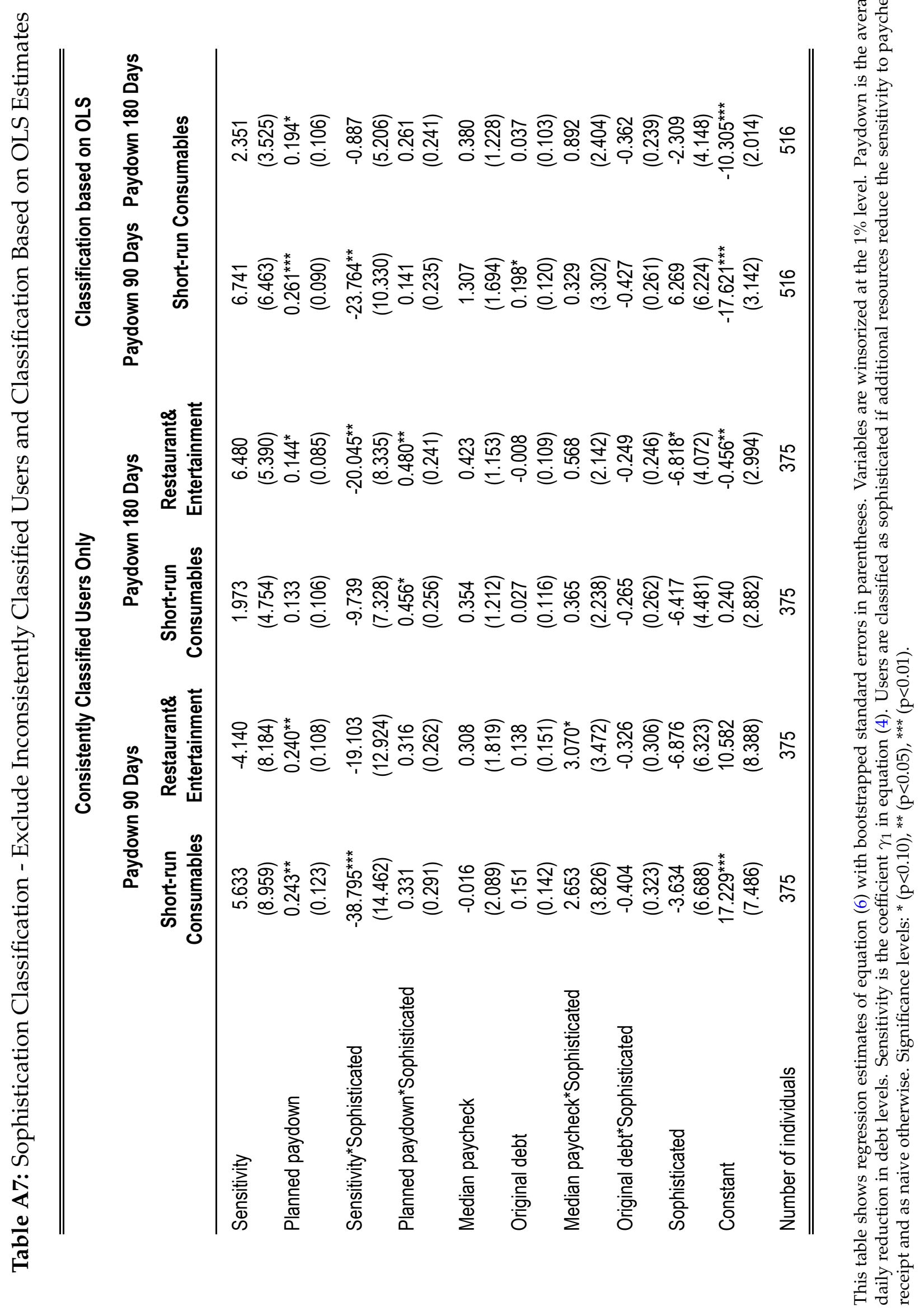

